\title{
Settling for Less out of Fear of Being Single
}

by

Stephanie Spielmann

A thesis submitted in conformity with the requirements for the degree of Doctor of Philosophy

Department of Psychology

University of Toronto

(C) Copyright by Stephanie Spielmann 2013 


\title{
Settling for Less out of Fear of Being Single
}

\author{
Stephanie Spielmann \\ Doctor of Philosophy \\ Department of Psychology \\ University of Toronto
}

2013

\begin{abstract}
The present research explores a novel construct of fear of being single, without a romantic partner. This research demonstrates that those who fear being single may lower their relationship standards without realizing it, even accounting for constructs typically examined in relationship research such as anxious attachment and neuroticism. Study 1 explored the content of people's thoughts about being single. Studies $2 \mathrm{~A}$ and $2 \mathrm{~B}$ involved the development and validation of the Fear of Being Single scale. Study 2C provided preliminary support for the hypothesis that fear of being single predicts settling for less in ongoing relationships, showing that fear of being single predicted greater dependence on unsatisfying relationships. Studies 3A and 3B explored the predictive ability of fear of being single for self-reported dating standards. Across both samples, fear of being single was unrelated to self-reported standards for a mate, with the exception of consistently higher standards for parenting. However, Studies 4 and 5 explored romantic interest in targets that were manipulated to vary in responsiveness (both Studies 4 and 5) and physical attractiveness (Study 5 only). These studies found that fear of being single consistently predicted higher levels of romantic interest in less responsive and less attractive dating targets. Taken together, the present research suggests that fear of being single is a meaningful predictor of settling for less in relationships.
\end{abstract}




\section{Acknowledgments}

Thank you to my dissertation committee members, Poppy Lockwood, Marc Fournier, and Emily Impett, for your time and continued mentorship over the years. Your guidance on this project has been invaluable. Thank you most of all to my advisor, Geoff MacDonald. Your endless support, advice, and mentorship have been key factors in my growth as an academic and as a person. And you had a knack for making it fun along the way! I feel truly honoured to have been mentored by you over the years, and I'm proud to call you my friend and colleague.

To all of my grad school cronies, I would never have survived without you! My subground office mates, you were the only perk of working in the dark depths of the basement. And thank you to the greatest lab mates around, Jessica Maxwell and Samantha Joel. Furthermore, I am so grateful for the friendship and support of Jessica Remedios (my "work spouse”), Renée Biss, Marieke van Heugten, Kris Romero, and Trevor Fernandes. We've shared so many laughs, rants, and pints over the years, and I have no doubt that our friendship will last through the ages.

Thank you to my family for always being my biggest cheerleaders. Your support has come in many forms, and I appreciate all of it. Thank you to my parents Ruth and Dick Heeg, Roger Spielmann, and Serge and Joan Paquin. You have always encouraged me in academics and in life, and provided all the tools for me to do my best. Dad, we're the two coolest members of the Dr. Spielmann club! Thank you also to my sisters Melissa Stringer and Jennifer Colpitts, and their beautiful families, for reminding me what life, love, and laughter is all about. And of course, thank you all for being my first participants when I gave you Rorschach tests at age four. Sorry I deemed you all "crazy." 
Most of all, I am eternally grateful for the love and support of my husband Daniel Paquin. You have supported me through the best and worst of times. Thank you for being my rock, and never allowing me to quit (no matter how many times I threatened to). I'm so lucky to have you, and I look forward to the next chapters of our life together. 


\section{Table of Contents}

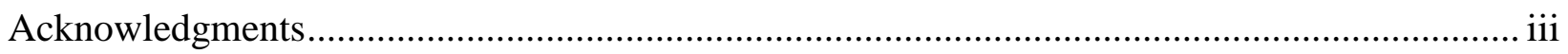

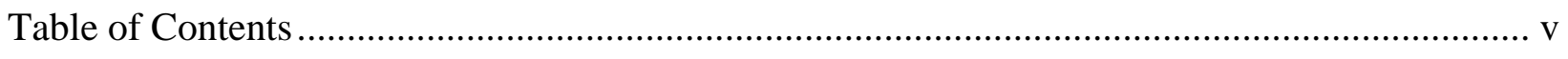

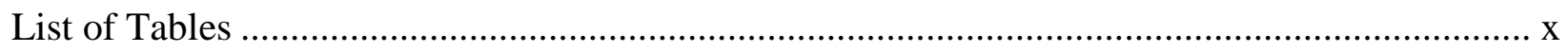

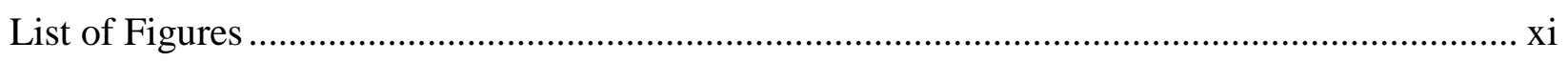

List of Appendices ............................................................................................................ xii

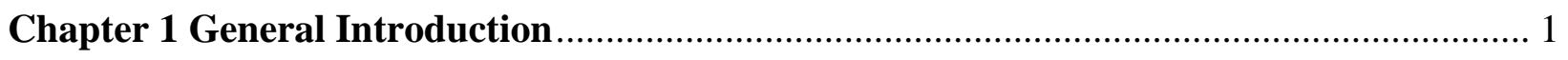

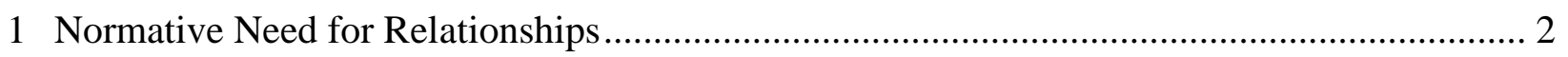

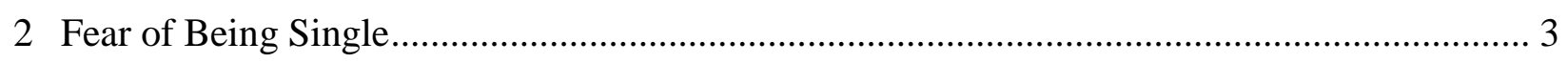

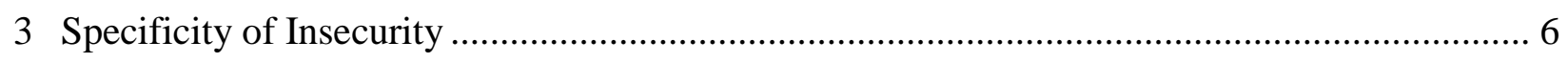

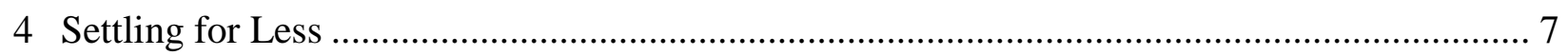

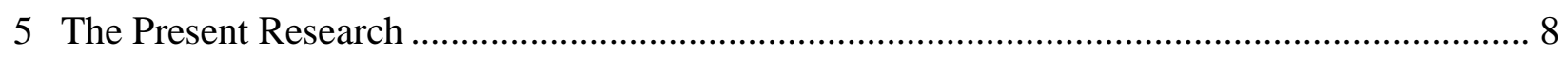

Chapter 2 Exploring the Content of Concerns about Singlehood ....................................... 10

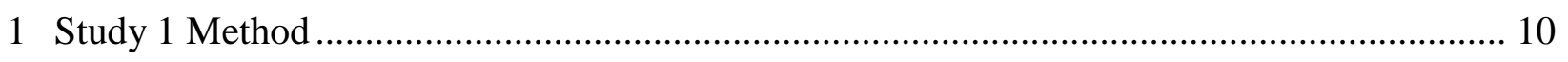

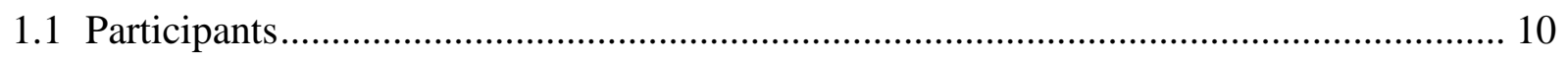

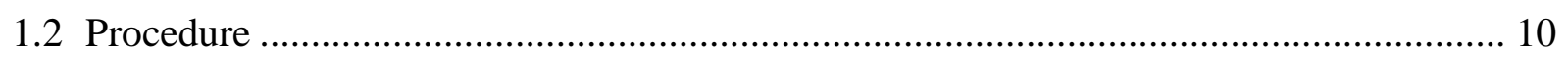

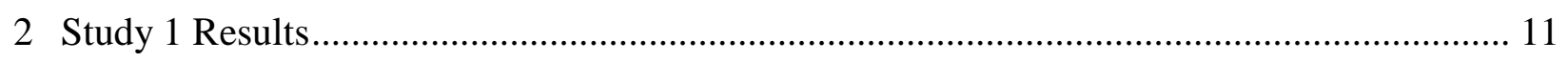

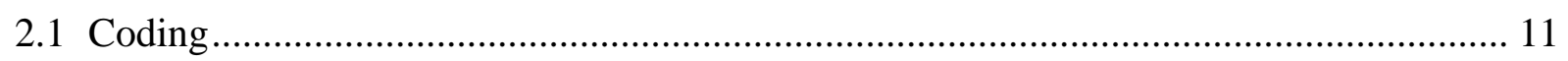

2.2 Open-ended Responses about Fear of Being Single ....................................................... 11

2.3 Predicting Themes from Age, Sex, and Relationship Status ........................................... 15

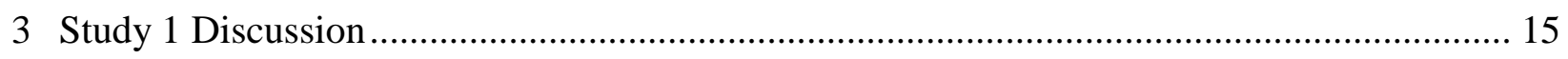

Chapter 3 Development and Validation of the Fear of Being Single Scale .......................... 17

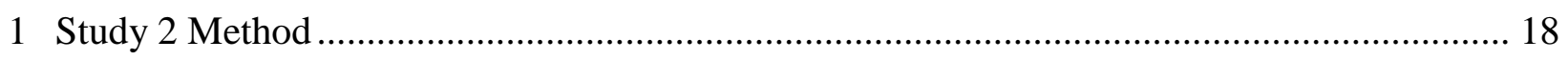

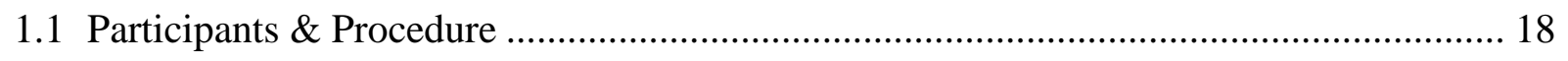




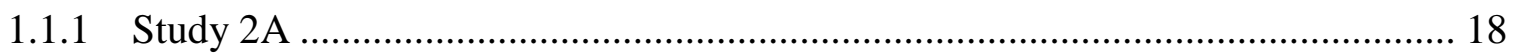

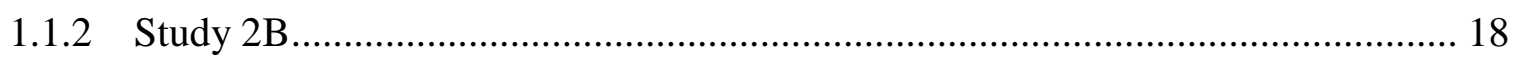

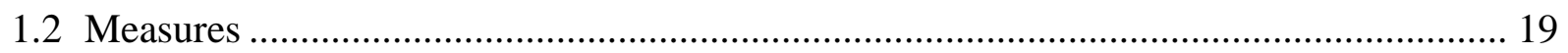

1.2.1 Fear of Being Single Scale............................................................................ 19

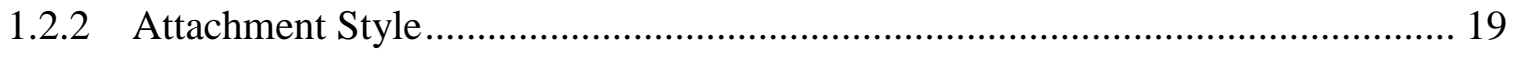

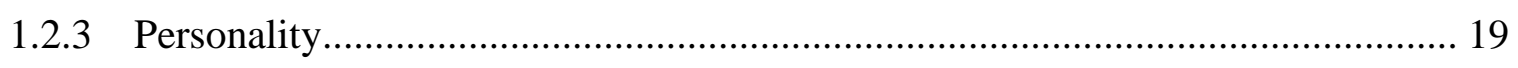

1.2.4 Relationship Contingent Self-esteem................................................................... 20

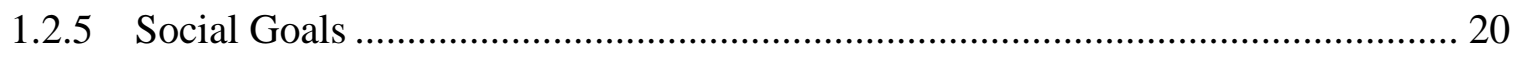

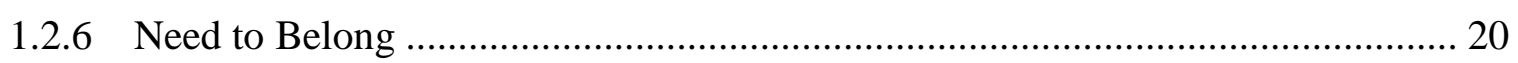

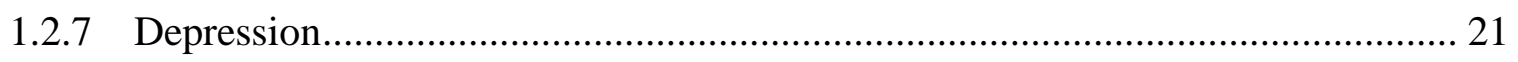

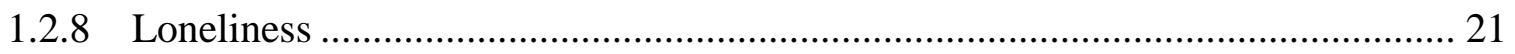

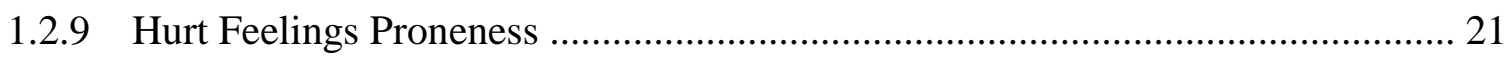

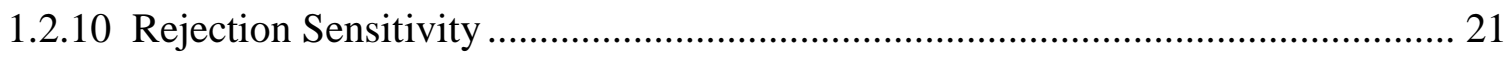

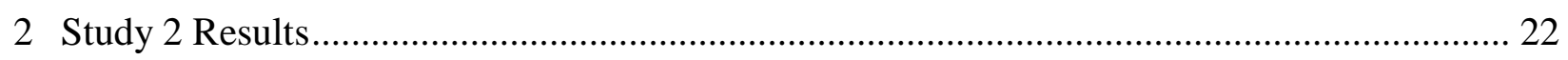

2.1.1 Refinement of the Initial Scale: Factor Analyses ............................................... 22

2.1.2 Validation of the Final Scale: Confirmatory Factor Analyses .............................. 24

2.1.3 Convergent and Discriminant Validity …………………............................... 24

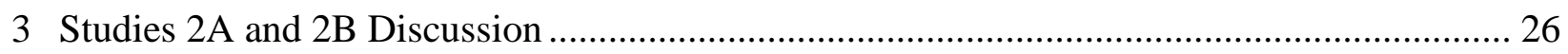

Chapter 4 Settling for Less: Relationship Dependence …………........................................ 27

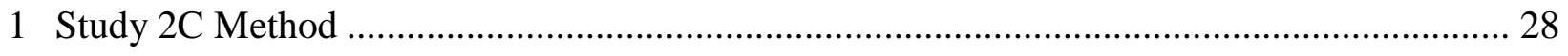

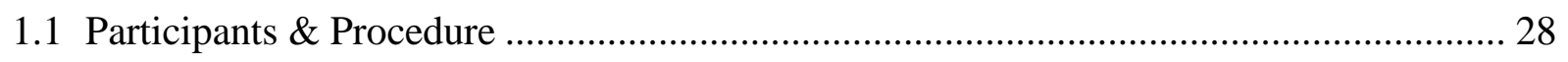

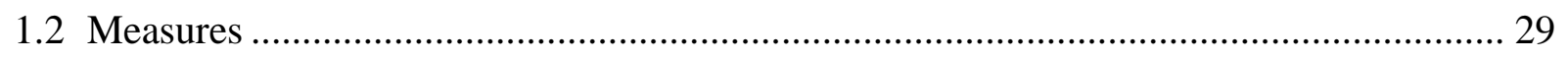

1.2.1 Relationship Satisfaction .............................................................................. 29

1.2.2 Relationship Dependence............................................................................ 29

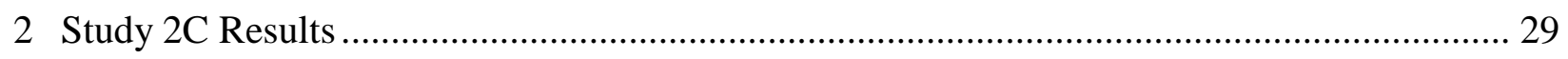

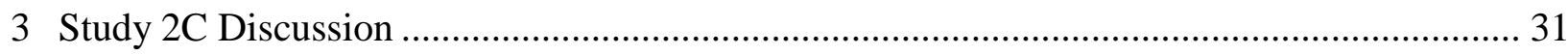




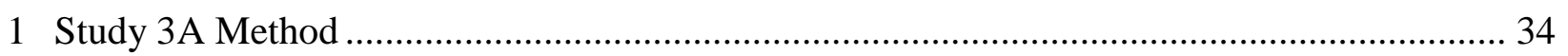

1.1 Participants \& Procedure .................................................................................. 34

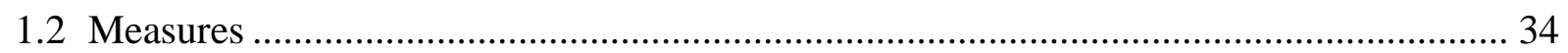

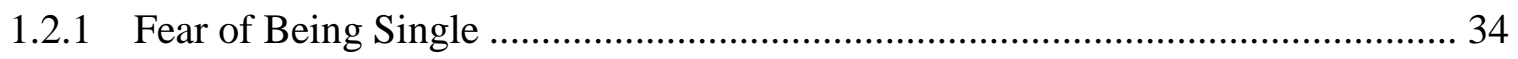

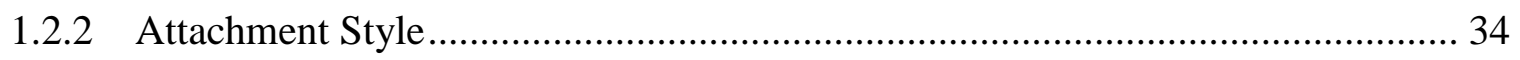

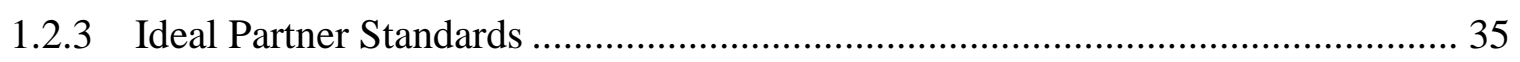

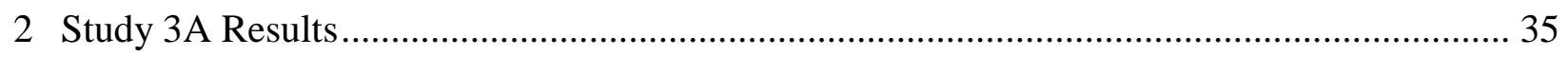

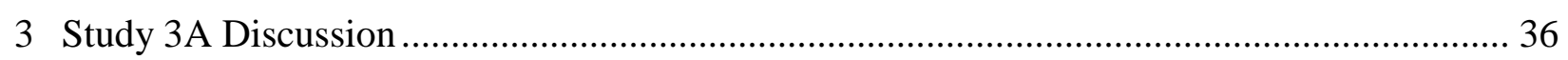

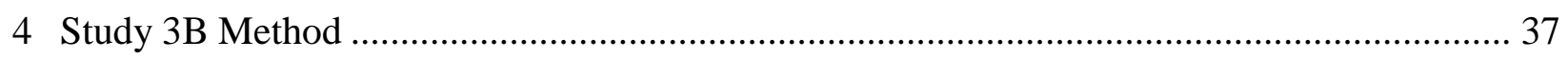

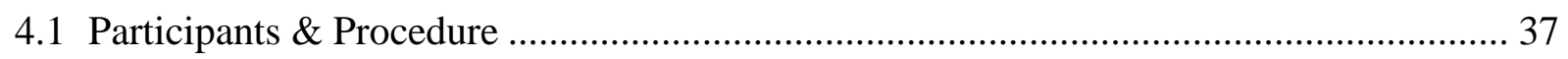

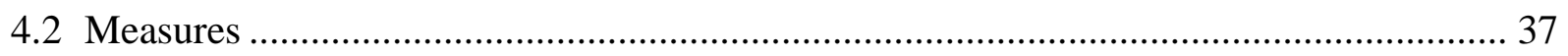

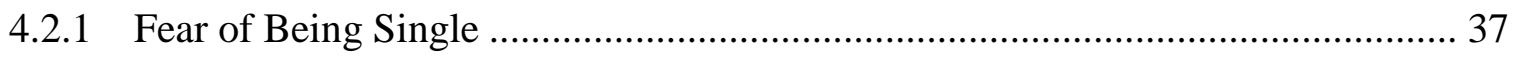

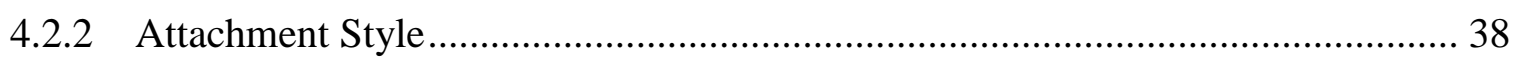

4.2.3 Ideal Partner Standards ........................................................................... 38

4.2.4 Minimum Partner Standards .................................................................... 38

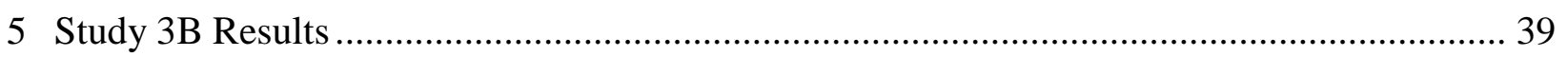

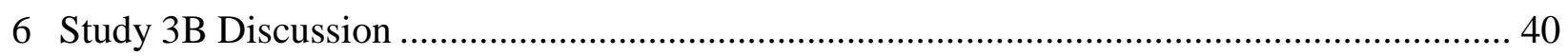

Chapter 6 Settling for Less: Relationship Initiation............................................... 42

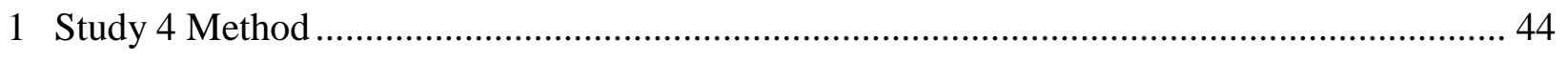

1.1 Participants \& Procedure ............................................................................... 44

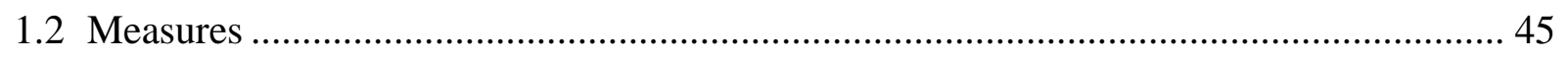

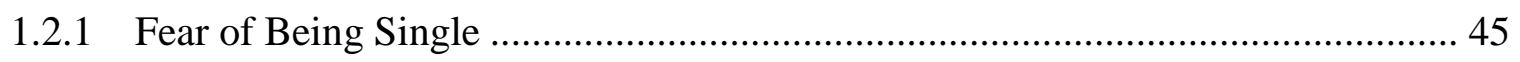

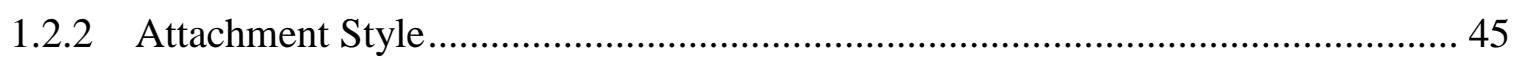

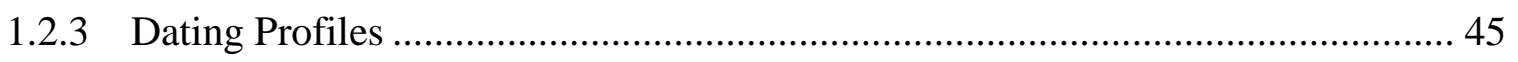

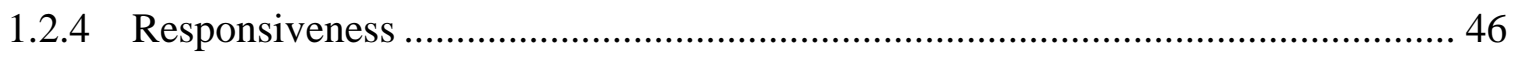




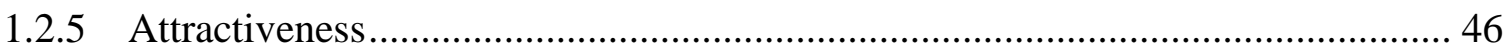

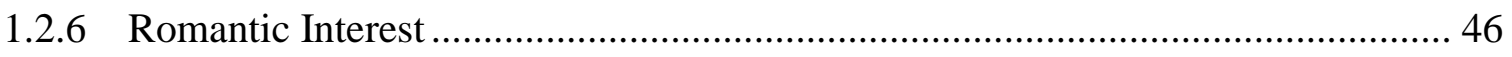

1.2.7 Anticipated Romantic Success ........................................................................ 46

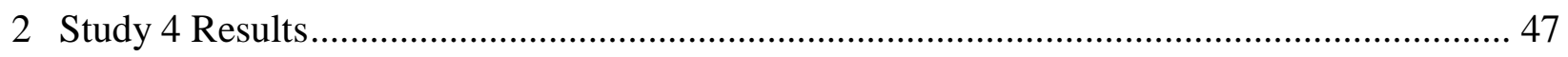

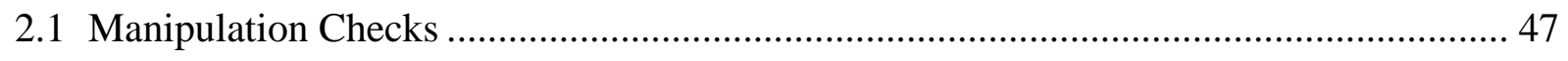

2.1.1 Perceived Responsiveness ......................................................................... 47

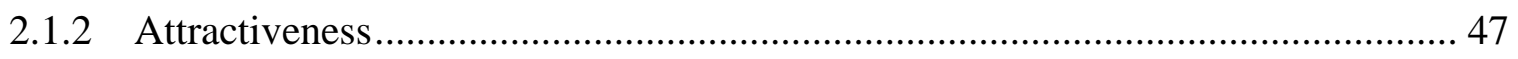

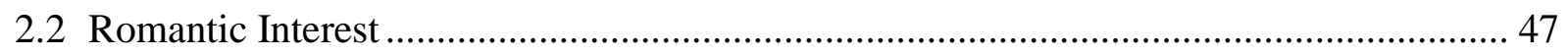

2.3 Anticipated Romantic Success ................................................................................... 49

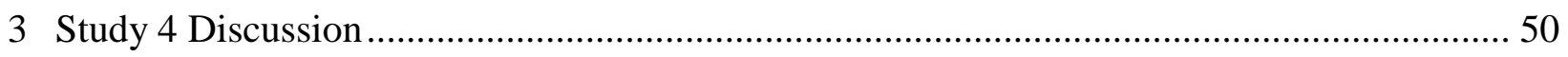

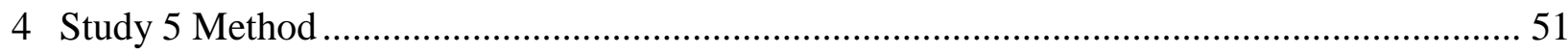

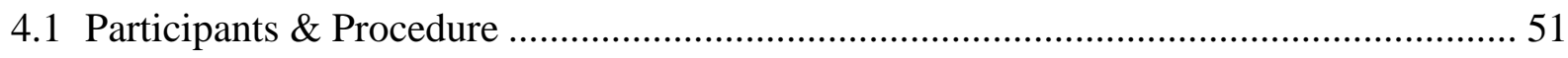

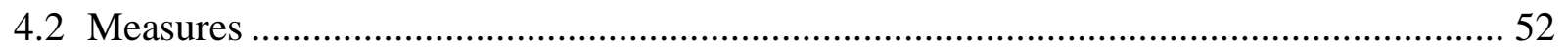

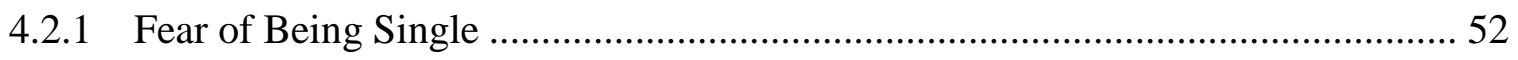

4.2.2 Attachment Style ....................................................................................... 52

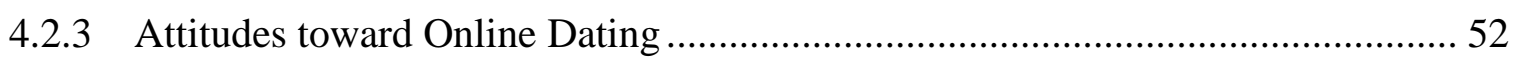

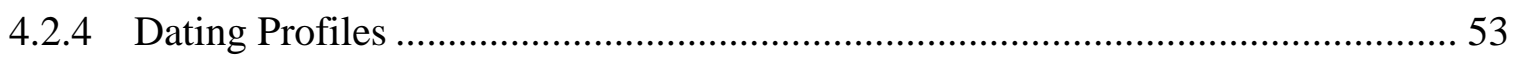

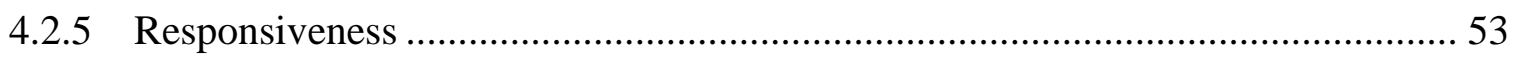

4.2.6 Attractiveness ........................................................................................ 53

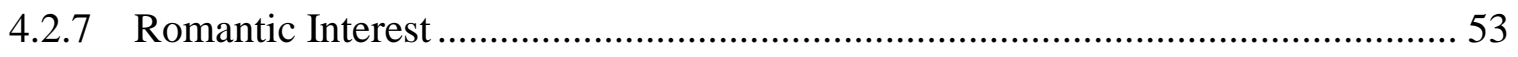

4.2.8 Anticipated Romantic Success ...................................................................... 54

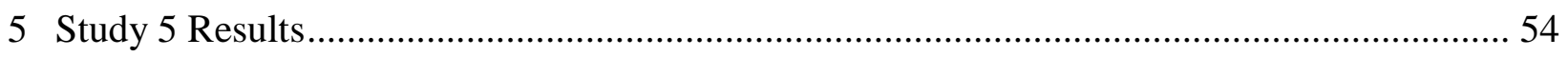

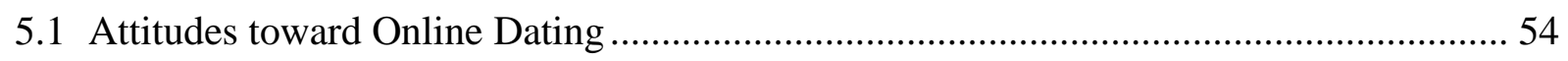

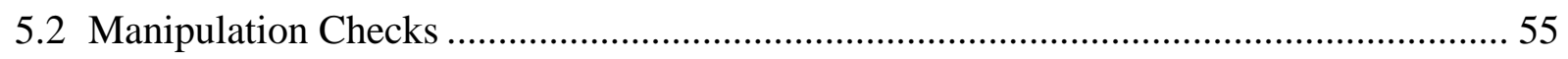

5.2.1 Perceived Responsiveness ......................................................................... 55

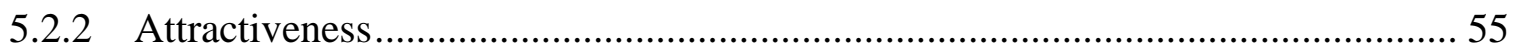




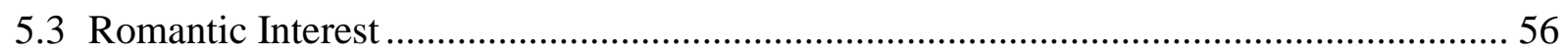

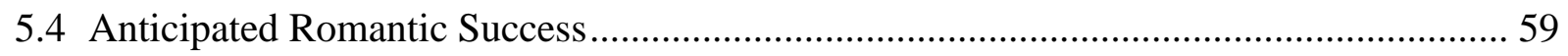

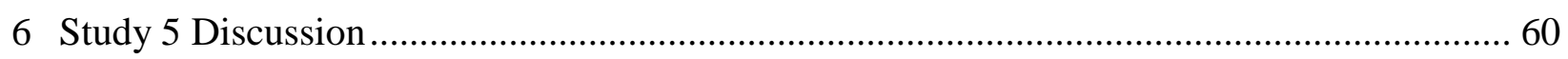

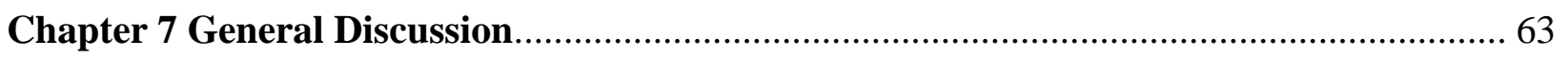

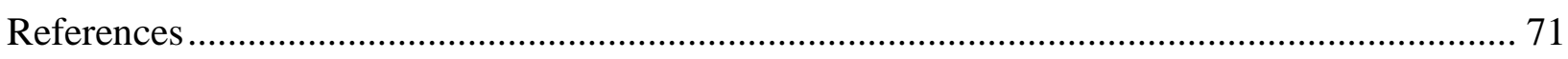

Appendix A: Original items for Fear of Being Single scale ............................................. 84 


\section{List of Tables}

Table 1: Frequencies and examples of themes from open-ended narratives in Study $1 \ldots \ldots . . .12$

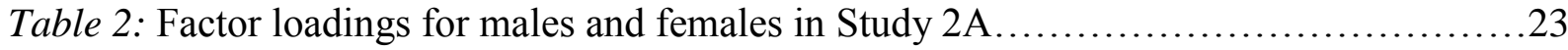

Table 3: Convergent and discriminant validity of Fear of Being Single scale (Studies 2A

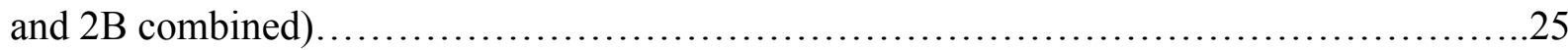

Table 4: Correlations between fear of being single and dating standards in Study 3A........36

Table 5: Correlations with fear of being single in Study 3B............................... 


\section{List of Figures}

Figure 1: Dependence on a relationship as a function of relationship satisfaction and fear

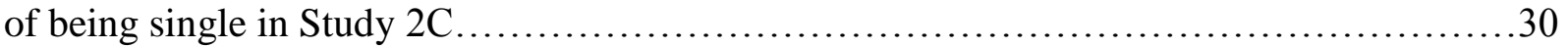

Figure 2: Romantic interest as a function of target responsiveness and fear of being single

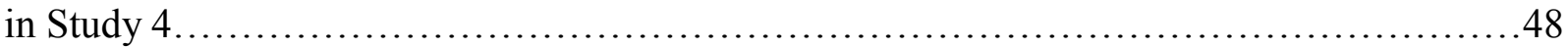

Figure 3: Romantic interest as a function of target responsiveness and fear of being single

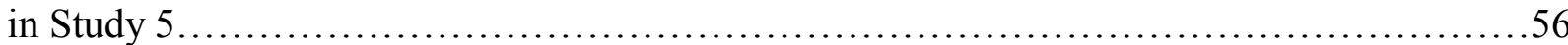

Figure 4: Romantic interest as a function of target attractiveness and fear of being single in Study 5 


\section{List of Appendices}

Appendix A: Original items for Fear of Being Single scale $\ldots \ldots \ldots \ldots \ldots \ldots \ldots \ldots \ldots \ldots \ldots \ldots . \ldots 4$ 


\section{Chapter 1}

\section{General Introduction}

"Single women lead lonely, depressing, and incomplete lives. Their unhappiness increases exponentially with each passing birthday, because past a certain age a woman is 'used up.' All women are desperate to marry or remarry because marriage is their only real chance for security and happiness" (Anderson \& Stewart, 1994, p. 64)

Anderson and Stewart discuss the subtle yet destructive myths about singlehood that are arguably as much common currency today as they were 20 years ago. The myth is that singles all yearn for a relationship and they suffer or lack without it. Indeed, Western society maintains an ideology that the romantic relationship is the most important social relationship (Day, Kay, Holmes, \& Napier, 2011; DePaulo \& Morris, 2005). Such beliefs would seem to promote fears about the consequences of not finding a romantic partner. How do people's concerns about ending up alone influence how they seek out and maintain relationships?

The present research explores the usefulness of a fear of being single construct for understanding relationship attitudes and behavior. I construe fear of being single as entailing concern, anxiety, or distress regarding the current or prospective experience of being without a romantic partner. This fear may manifest as an immediate concern about one's current relationship status or anxiety about the prospect of being single in the future. In this sense, even people in relationships may be affected by a fear of being single. The goal of the present research is, first and foremost, to establish fear of being single as a unique and valid psychological construct. Furthermore, I aim to explore the implications of fear of being single in important relationship domains. In particular, distress about not having a romantic relationship may promote an approach that any relationship is better than none. An important consequence of the fear of being single may be, therefore, to settle for less in relationships in order to gain and 
maintain a relationship.

Choosing whether to initiate, maintain, or dissolve romantic relationships involves complex decision making, such that individuals often weigh their options, and rely heavily on heuristics and emotions to make these decisions (Joel, MacDonald, \& Plaks, 2012). To the extent that one fears being single, daily relationship decisions may be driven by a need for relationships over other factors that typically predict commitment and romantic stability, such as the potential for high satisfaction or relationship quality (e.g., Le, Dove, Agnew, Korn, \& Mutso, 2010; Rusbult, Martz, \& Agnew, 1998). I demonstrate in the present research that fear of being single predicts the tendency to engage in decisions that seem to prioritize relationship status over relationship quality, colloquially known as "settling for less." To better understand how some forms of desire for relationships may lead to lower quality mate selection, it is helpful to first understand normative needs for relationships.

\section{Normative Need for Relationships}

Desire for intimate relationships, and concern about the status of one's relationships, is a normative human process. Because of the importance of social connection to survival and reproduction in our evolutionary past (Caporeal, 2001; Foley, 1995), humans require meaningful and persisting associations with others for both physical and psychological well-being (Baumeister \& Leary, 1995). A lack of social connection is associated with negative emotional states (Blackhart, Nelson, Knowles, \& Baumeister, 2009), impairments in self-regulation (Baumeister, DeWall, Ciarocco, \& Twenge, 2005), hostility and aggression (Chow, Tiedens, \& Govan, 2008; Leary, Twenge, \& Quinlivan, 2006), and negative health outcomes such as increased risk of contracting illnesses and greater risk of mortality (Cohen, Doyle, Skoner, Rabin, \& Gwaltney, 1997; House, Landis, \& Umberson, 1988). 
Beyond a broad need for social connection, attachment theory specifically highlights the need for close bonds with trusted attachment figures (Bowlby, 1969; Mikulincer \& Shaver, 2007). The attachment system is rooted in infant-caregiver connections, and becomes activated in response to distress and threat in order to prompt individuals to seek security and comfort from caregivers (Ainsworth \& Bell, 1970; Bowlby, 1969). The attachment system extends beyond the infant-parent association, such that youth and adults form attachments with close others and construe them as attachment figures (Fraley, Brumbaugh, \& Marks, 2005; Hazan \& Shaver, 1987).

It is therefore a natural part of human development to want and need someone who can serve as a secure base from which to explore freely and securely and a safe haven to provide comfort and security in times of distress (Mikulincer \& Shaver, 2007). People thus have deeplyrooted, intrinsic motivations to gain and maintain close social connections. These basic biological and psychological pressures for social connection may also contribute to fears of being single.

\section{Fear of Being Single}

Fear of being single is defined in the present research as concern, anxiety, or distress regarding the current or prospective experience of being without a romantic partner. Although an important component of lay understanding of relationship dynamics, fear of being single has been an underexplored phenomenon in the quantitative research literature. However, past research involving qualitative assessments, such as interviews and narrative analyses, have documented such anxieties about singlehood. Indeed, this qualitative research suggests that, for a subset of individuals, a stable relationship status is the primary source of psychological security, with its absence being a source of distress and anxiety (Cole, 1999). Societal and family 
pressures, combined with insecurity and self-doubt, cause some people to struggle to achieve a "comfortable definition of the self as a single person" (Schwartzberg, Berliner, \& Jacob, 1995, p. 5).

Combine the intrinsic desire for connection with the social stigma of being single (e.g., DePaulo \& Morris, 2005), and singlehood has the potential to be a distressing state that can provoke feelings of isolation on multiple fronts. Schwartzberg and colleagues (1995) explain that distress about being single may be a prevalent response given that one's personal and social identity are typically socialized to be tied to relationship status. For instance, quantitative research has demonstrated a well-defended ideology of the committed relationship, such that Western societies endorse and defend committed romantic relationships as the most important adult relationships (Day et al., 2011; DePaulo \& Morris, 2005). Single people recognize that others expect them to be in relationships (Cole, 1999; Sharp \& Ganong, 2011). Furthermore, most young adults expect that they will marry (DePaulo \& Morris, 2005), and the majority of Americans do (U.S. Census Bureau, 2010). Essentially, it is a couples' world, and it may be difficult to live single within it. Studies on women's experiences with singlehood have found that the sense of having missed an important life transition leaves many single women suffering intraand interpersonal sanctions and feeling uncertain about their futures (Sharp \& Ganong, 2007). In fact, scholars on singlehood note that it is often considered as a deficit state, marked by the lack of a relationship rather than as an entity of its own (Reynolds \& Taylor, 2005; Reynolds \& Wetherell, 2003).

Psychotherapist Marcy Cole (1999) conducted extensive interviews with never-married women in their thirties who desired marriage and a family. Cole found significant variation in the lived experiences of singlehood. She noted that in terms of emotional responses to being single, participants tended to fall into one of three distinct groups. The largest group consisted of those 
who felt ambivalent about being single. Women in this group had fluctuating emotional responses to singlehood, acknowledging the positive features such as autonomy and independence, but also noting the frequent bouts of loneliness and judgment from others. The second group consisted of those who approached singlehood with empowerment, maintaining a positive sense of self regardless of their relationship status. Lastly, some women experienced chronic and intense anxiety, despair, and self-doubt in response to being single. Thus, qualitative research suggests individual differences in the fear of being single that may have meaningful implications for relationship choices.

Despite its value, an important limitation to past research on the psychological experience of singlehood is that the majority of this research has been conducted retrospectively, focusing on the reflected experiences of single, middle-aged adults. As such, the past research exclusively explores the experiences of those who have actually ended up single. By definition, individuals who compromised their relationship standards to resolve fears of being single and who continue to maintain those relationships would have escaped the purview of past researchers. I propose in the present research, however, that those who fear being single may be desperate not just to initiate relationships but to maintain them even at significant cost. Thus, the focus of the present research is on the process of managing the fear of being single, rather than the outcome of ending up alone. The present research applies a mixed methods approach to the exploration of concerns about singlehood that addresses a wider range of age and experience than has typically been explored.

Past research on the lived experience of singlehood has also been conducted almost exclusively with female participants. However, I propose that fear of being single is not a uniquely female phenomenon. In fact, in a study of unmarried heterosexual adults over 30 years old, men had stronger desires for marriage than women because they had weaker social support 
(Frazier, Arikian, Benson, Losoff, \& Maurer, 1996). Both sexes also experience discrimination for being single. For instance, men and women are both evaluated more negatively when single compared to when coupled (Hertel, Schütz, DePaulo, Morris, \& Stucke, 2007). Single men are also discriminated against as much as single women (if not more) in contexts such as tenant leasing preferences (Morris, Sinclair, \& DePaulo, 2007). Therefore, in terms of emotional and psychological needs to find and maintain intimate relationships, there should not necessarily be differences between men and women.

\section{Specificity of Insecurity}

I argue that fear of being single provides a theoretically meaningful level of specificity not taken into account with other measures of insecurity, such as low self-esteem and anxious attachment. That is, fear of being single may more directly tap into relationship-specific outcomes because it is a relationship-specific construct. Gillath and colleagues (Gillath, Hart, Noftle, \& Stockdale, 2009; Noftle \& Gillath, 2009) discuss the benefit of using an assessment at the same level of specificity as the outcome, in order to account for a unique amount of variance typically overlooked with trait measures. Indeed, their state measures of attachment were found to be consistent with trait measures, although representing unique statistical constructs (Gillath et al., 2009). I propose that a key difference between fear of being single and anxious attachment may be the specificity of the desired attachment figure. While those who fear being single by definition are focused specifically on romantic attachment figures, anxiously attached individuals may be focused on receiving comfort and reassurance from a broader range of attachment figures including peers and family members (e.g., Cox \& Arndt, 2012; Cox, Arndt, Pyszczynski, Greenberg, Abdollahi, \& Solomon, 2008; Fraley \& Davis, 1997; Markiewicz, Lawford, Doyle, 
\& Haggart, 2006). Therefore, when trying to predict behavior in romantic relationship contexts, fear of being single may add a level of specificity above and beyond trait anxious attachment.

\section{$4 \quad$ Settling for Less}

Do people's concerns about ending up alone lead them to desperately seek out relationship partners and cling to a relationship once they have one? People tend to have expectations for their relationships in domains such as physical attractiveness, status/resources, and responsiveness and intimacy potential (e.g., Fletcher \& Simpson, 2000; Fletcher, Simpson, Thomas, \& Giles, 1999). There is mixed evidence, however, regarding whether feelings of insecurity, such as low self-esteem and anxious attachment, promote more or less willingness to settle for less in relationships. Those who are less secure about their own value as romantic partners tend to be more willing to compromise their standards in a relationship (Campbell, Simpson, Kashy, \& Fletcher, 2001; Regan, 1998). Moreover, decreased self-esteem as a consequence of romantic rejection has been associated with lower mating aspirations (Kavanagh, Robins, \& Ellis, 2010). Similarly, individuals higher in anxious attachment tend to remain committed to relationships that do not satisfy their needs (Slotter \& Finkel, 2009). Hirschberger, Florian, and Mikulincer (2002) likewise found that male and female students who had lower selfesteem reported lower requirements on a number of partner traits, such as intellect, attractiveness, social status, and interpersonal skills. However, following a mortality salience threat, it was those with high self-esteem who were more willing to compromise their ideal standards rather than those with low self-esteem. Furthermore, Tolmacz (2004) found that anxiously attached individuals were less willing to compromise their ideal mate standards.

The previous literature therefore yields mixed results about insecurity and the willingness to settle for less. These inconclusive findings highlight the need for a more specific measure of 
relational insecurity tapping into willingness to compromise one's standards. Better understanding the phenomenon of fearing being single may shed light on motivations to settle for less, and contexts in which this will be the case. I hypothesize that those who fear being single may be willing to accept lower quality mates in order to avoid being single. The danger to this strategy, however, is that having a lower quality partner than one would ideally like predicts lower relationship quality and greater likelihood of relationship dissolution (Campbell et al., 2001; Fletcher, Simpson, \& Thomas, 2000).

\section{The Present Research}

The primary goal of the present research was to better understand the fear of being single construct. To this end, I sought to develop and validate a measure of fear of being single, and then to explore the effects of fear of being single on people's willingness to settle for less when (1) maintaining relationships with less satisfying partners, (2) evaluating relationship ideals, and (3) selecting dating partners and initiating relationships. In general, I hypothesized that individual differences in fear of being single would predict willingness to settle for less. Specifically, stronger fear of being single should be associated with greater willingness to settle for lower quality relationships.

Study 1 involved a qualitative study design to explore people's thoughts and feelings about being single. Thematic analyses of open-ended responses highlighted the frequency and primacy of specific concerns about being single and informed the creation of a Fear of Being Single scale in Study 2. Studies 2A and 2B involved factor analyses and validation of the Fear of Being Single scale across two independent samples. I examined the validity of the scale by testing whether individual differences in fears of being single are associated (though not redundant) with measures of interpersonal anxiety and negative affect, such as anxious 
attachment and neuroticism, social avoidance goals, and general interpersonal sensitivities. Study 2C assessed a subsample of participants in relationships from Studies $2 \mathrm{~A}$ and $2 \mathrm{~B}$, examining their current relationship satisfaction and relational dependence. I hypothesized that those who fear being single would be more dependent on their romantic relationships, regardless of how satisfied they felt in their relationship. Studies 3A and 3B explored people's standards for an ideal partner (3A) and the minimum standards for which they would settle (3B). I expected that fear of being single would predict setting lower standards for a partner. However, I also considered the possibility that fear of being single may not predict self-report standards due to the psychological discomfort of consciously acknowledging the willingness to settle for less. Finally, Studies 4 and 5 explored how those who fear being single evaluate less desirable dating targets in the context of online dating. In two online dating tasks, participants evaluated their romantic interest in targets who appeared either high or low in responsiveness (Studies 4 \& 5) and who were either physically attractive or unattractive (Study 5). I hypothesized that those who feared being single would be more likely to express romantic interest in less desirable targets compared to those who did not fear being single. 


\section{Chapter 2}

\section{Exploring the Content of Concerns about Singlehood}

My first step in understanding the fear of being single involved the creation and validation of a reliable assessment tool. In order to inform items for a quantitative measure of fear of being single, I began with an open-ended survey of individuals' thoughts about being single. The purpose of Study 1 was to explore the extent to which people report anxiety about being single and which aspects of being single may or may not concern them. Unlike other qualitative studies on the experience of being single, I invited participants of all ages, sexes, and relationship experience. Participants were recruited online and asked to describe their feelings about being single. Participants' responses were coded for common themes to better understand the fear of being single.

\section{$1 \quad$ Study 1 Method}

\subsection{Participants}

Participants were 153 individuals (27 males, 126 females), recruited through online forums such as Craigslist.org. Participants were entered into a draw for a $\$ 50$ gift certificate. One single, female participant was excluded because she was younger than 18 years of age, despite the age requirement in the recruitment ad. The age of the remaining participants ranged from 18 to $59(M=30.5, S D=10.8)$. Of the 152 participants, 48 were currently single, 20 reported they were casually dating, 57 were exclusively dating, 10 were engaged, and 17 were married.

\subsection{Procedure}

Participants were asked to think about the extent to which they "fear being alone (i.e., single, without a romantic partner)." Participants were asked to explain their feelings in an open- 
ended manner, providing as much detail as possible. They were asked to indicate specifically what they fear, or do not fear, about being single.

\section{Study 1 Results}

\subsection{Coding}

The open-ended narratives were coded by two independent raters, blind to attachment style and fear of being single ratings. Raters coded the narratives for content related to the specific aspects of being single that participants reported as concerns or advantages. The coding was data-driven, such that coding categories were developed based on the comments provided by participants. Each narrative received as many codes as were applicable, with coding indicating either the presence or absence of a theme, rather than the frequency with which a theme was present within a given narrative. Cohen's kappa agreement between raters ranged from .31 to 1.00 across themes, with an average agreement of .71 , reflecting reasonably good agreement overall (e.g., Fleiss, 1981; Landis \& Koch, 1977). I personally resolved disagreements between raters. Only one theme scored lower than .50 in agreement, and I agreed consistently with one of the coders on this theme.

\subsection{Open-ended Responses about Fear of Being Single}

Table 1 summarizes participants' responses with examples for each theme. When discussing whether or not they fear being single, a large proportion of individuals (39\%) made explicit claims about not fearing being single, while approximately $37 \%$ explicitly indicated a fear of being single to some degree. Some individuals expressed current concerns about being single, some reported ambivalent feelings, and some reported expecting singlehood to be a growing concern as they got older.

When discussing the aspects of being single which cause them anxiety, the most 
Table 1. Frequencies and examples of themes from open-ended narratives in Study 1

\begin{tabular}{rc}
\hline $\begin{array}{c}\text { Percent } \\
\text { Reported }\end{array}$ & Example \\
\hline
\end{tabular}

Presence of Fear of Being Single

Explicit no fear being single $\quad 38.8 \% \quad$ "I don't fear being alone...Having company is not the same as being fulfilled as a person. I believe that part of fulfillment is knowing you are capable to function on your own." (female, single, 29 years old)

Explicit fear of being single $\quad 18.4 \% \quad$ "I worry what my future will be. Will I just end up another old lady forgotten and alone?" (female, single, 58 years old)

Ambivalent feelings about

$11.8 \%$ "I am very family oriented and have life long being single friends thus I will never be truly alone. However the thought of being single without a romantic partner somewhat bothers me. I also strongly feel that having a romantic relationship with a partner is tiresome and involves too much work. So sometimes I am bothered by being alone but also feel relief." (female, single, 23 years old)

Anticipate being fearful in

"I tend to not worry so much about whether I am the future alone or single at the moment, but do have a fear of being alone when I am old. Singleness at 25 years old does not sound so bad, but to be single forever sounds terrible." (female, dating, 25 years old)

\section{Reasons for Fear of Being Single}

Fear not having the longterm companionship of an intimate partner

Fear losing current partner
$40.1 \%$ "I fear that there will be no one there that I can share intimacy with like cuddling, hugs and kisses and the fact that there is somebody that is ready to do anything or go anywhere with you." (female, dating, 23 years old)

$11.8 \%$ "I do sometimes fear the possibility that something will happen to my husband, such as a grave illness or an accident....I can't imagine the thought of experiencing something joyful and not being able to share it with him. Our domestic rhythms revolve around each other, and if I have 
Fear growing old alone

Fear never having children and a family

Fear feeling worthless or bad about themselves

Fear friends and family aren't enough to ease anxieties about being single

Fear people will judge them negatively if single for too long

Won't have as much sex if single

Will suffer financially if single

Any relationship, even if bad, is better than being alone

\section{$11.2 \%$}

$6.6 \%$

$6.6 \%$

$4.6 \%$

$3.9 \%$

$2 \%$

$2 \%$

"My biggest fear is that I will not be able to support myself financially." (female, dating, 48 years old)

$0.7 \%$

"I think being with someone (in a relationship) is worth whatever else comes along with it." (male, dating, 38 years old)

to spend the evening alone, time seems to pass more slowly, and the night seems shapeless and devoid of routine." (female, married, 28 years old) awful it would be to be alone as an elderly person." (male, dating, 47 years old) great parts of life: marriage, children, family." (female, dating, 27 years old) unlovable, and never being loved (female, dating, 57 years old)

"Although every relationship has its costs and benefits, romantic relationships seem to possess a unique set of benefits that can't be achieved through other types of interactions." (female, dating, 23 years old)

"There seems to be a societal expectation, and no doubt an extended family expectation, that an attractive woman such as myself should not remain unattached indefinitely. The 'old spinster' cliché comes to mind." (female, single, age not reported)

"I really miss making love! Just because you get older, it does not mean that passion takes a backseat." (female, single, 49 years old)

"Regardless if I have a significant other or not in the future, I will always have people who love me and who I love." (female, dating, 18 years old)

\section{Reasons for No Fear of Being Single}

Having friends and family to turn to eases anxieties about being single 
Being alone is a better alternative than being in a bad relationship

No longer fearing being alone due to a past experience with loneliness, such as being single or in a bad relationship
8.6\% "I have grown enough emotionally and psychologically to know that I would rather be on my own than be a part of another unhealthy relationship." (female, single, 35 years old)

8.6\% "In the past, I have relied on men to make me happy, and when they have let me down, I felt no control over myself.... Upon doing a lot of soul searching, I have come to realize that my state of happiness depends on me. I am responsible for finding peace within myself so I'm no longer dependent on someone else to make me happy or make me feel worthy." (female, dating, 27 years old)

Religious beliefs ease anxieties about being single
$1.3 \% \quad$ "I never feel alone because God is always there." (female, married, 29 years old)

commonly cited concern was lacking companionship and intimate connection with a partner. The other most commonly cited worries were concerns about losing a current partner, growing old alone and its associated complications, missing out on having children and a family, judging oneself negatively - as well as being judged negatively by others - for being unable to find a partner, and concerns that a romantic partner provides unique comfort that friends and family cannot. A small proportion also reported concerns about lacking financially and sexually without a partner, and one participant reported that the benefits of a relationship are worth any associated costs.

Finally, when discussing reasons why being single does not cause them anxiety, individuals were most likely to cite factors such as having close friends and family to turn to in the absence of a romantic partner. Some participants also indicated that being in a bad relationship would be a greater concern than being single, or that their anxieties were attenuated by experiences of being single in the past or having a negative relationship experience that 
helped them realize being single would not be so bad. Lastly, a small proportion reported turning to religion to ease loneliness.

\subsection{Predicting Themes from Age, Sex, and Relationship Status}

I next explored whether the odds of reporting a specific concern, or lack thereof, about being single were predicted by participants' age, sex, or relationship status. For this analysis, relationship status was dummy coded such that those who were single and casually dating were coded as single and those who were seriously dating, engaged, or married, were coded as relationship. I conducted binary logistic regressions on each theme and simultaneously included age, $\operatorname{sex}(0=$ female, $1=$ male $)$, and relationship status $(0=$ single, $1=$ relationship $)$ as predictors.

Participant age positively predicted the odds of reporting concern about growing old alone, odds ratio $=1.04, p=.05$. Furthermore, participant age decreased the odds of saying that close friends and family members could ease concerns about being single, odds ratio $=.86, p=$ .01. Not surprisingly, being in a relationship increased the odds of fearing losing one's current partner, odds ratio $=16.08, p=.008$. Moreover, those in relationships were less likely to report that they would feel bad about themselves if they ended up single, odds ratio $=.07, p=.01$. There were no predictive effects of participant sex, and no other themes yielded significant effects.

\section{Study 1 Discussion}

The results of Study 1 shed light on the subjective experience of being single. Participants' open-ended responses revealed individual differences in the extent to which people report anxieties about being single and highlighted variability in the specific issues of concern. Among a variety of concerns about being single, the most marked fear was that of lacking love 
and companionship. Moreover, this concern emerged regardless of age, sex, and relationship status.

The primary feature of Study 1 was that it provided a novel insight into the specific types of concerns people have when it comes to being single. Compared to previous literature on singlehood, this study assessed prospective concerns about being single from participants of all ages, sexes, and relationship status. Validating my suggestion that fear of being single may be a more widespread phenomenon than past qualitative research has suggested, I found few differences in concerns among these different groups. Perhaps most importantly, participant sex did not predict any differences in self-reported concerns about being single. Therefore, long-term singlehood is clearly not a uniquely female concern. From the informative analysis of Study 1, I next aimed to develop a quantitative assessment tool for tapping into individual differences in fear of being single. 


\section{Chapter 3}

\section{Development and Validation of the Fear of Being Single Scale}

The primary purpose of Study 2 was to create and validate a scale assessing the fear of being single. I created a preliminary Fear of Being Single scale, informed by responses gathered in Study 1. I then conducted factor analyses to refine the scale to only the most representative items for both males and females. Lastly, I compared the final scale to a battery of established measures of insecurity, social avoidance, and interpersonal sensitivity to determine convergent and discriminant validity. Specifically, given that the fear of being single should tap into interpersonal insecurities more generally, I assessed convergent validity with measures of anxious and avoidant attachment, neuroticism, and measures of sensitivity such as loneliness, depression, and need to belong. Furthermore, because a key aspect of fear of being single is an emotional state contingent on one's relationship status, I also assessed convergent validity by having participants report their relationship contingent self-esteem. Finally, because fear of being single likely represents an avoidance, fear-based motivation (i.e., strong desire to avoid being single), I examined convergent validity with a measure of social avoidance goals. I examined discriminant validity with a measure of social approach goals, as fear of being single should not be associated with reward-based approach motivations. To conduct the factor analyses and to create a scale that was generalizable to the general community, I collected two independent samples of participants consisting of online community members (Study 2A) and university undergraduate students (Study 2B). 


\section{$1 \quad$ Study 2 Method}

\subsection{Participants \& Procedure}

Two independent samples of online and undergraduate participants were collected. Participants first indicated their age, sex, and relationship status, and then completed the items created for the initial version of the Fear of Being Single scale. Participants then completed the battery of measures discussed below in order to establish convergent and discriminant validity of the Fear of Being Single scale.

\subsubsection{Study $2 \mathrm{~A}$}

The sample of participants in Study 2A consisted of 304 individuals recruited through online forums (e.g., craigslist.org) in return for entry into a draw. Three participants younger than 18 were excluded for not satisfying age eligibility. The remaining 301 participants (66 males, 233 females, 2 unreported) ranged in age from 18 to 69 years old $(M=29.3, S D=9.7)$. One hundred thirty-one participants reported they were single, 31 were casually dating, 99 were exclusively dating, 7 were engaged, and 33 were married. Participants were primarily from Canada and the United States.

\subsubsection{Study 2B}

Study 2B consisted of 147 undergraduate students (39 male, 108 female) at the University of Toronto, participating in return for course credit. Participants ranged in age from 17 to 34 years old $(M=19.2, S D=2.7)$. One hundred and five participants were single, 9 were casually dating, 28 were exclusively dating, 3 were engaged, and 2 were married. 


\subsection{Measures}

All participants completed the following measures. Additional measures were collected from participants in relationships, which are discussed in Study 2C.

\subsubsection{Fear of Being Single Scale}

Prominent themes about being single obtained from participants in Study 1 were formulated into a series of 17 scale items (see Appendix A for full scale). Participants responded to each statement on a scale from 1 (not at all true) to 5 (very true).

\subsubsection{Attachment Style}

To gauge participants' degree of anxious and avoidant attachment, participants completed the Attachment Style Questionnaire (ASQ; Feeney, Noller, \& Hanrahan, 1994). Participants indicated on a scale from 1 (totally disagree) to 6 (totally agree) the degree to which they agreed with statements tapping into subscales of anxious attachment (e.g., "I worry that others won't care about me as much as I care about them;" 13 items; $M=3.40, S D=.88, \alpha=.88$ ) and avoidant attachment (e.g., "I prefer to depend on myself rather than other people;" 16 items; $M=$ 3.37, $S D=.65, \alpha=.81)$.

\subsubsection{Personality}

In order to examine the association of the fear of being single with established personality constructs, participants responded on a scale from 1 (disagree strongly) to 5 (agree strongly) to items assessing the Big 5 personality traits (BFI; John \& Srivastava, 1999), including neuroticism (e.g., "I see myself as someone who worries a lot;" 8 items; $M=3.17, S D=.81, \alpha=$ .84), openness (e.g., "I see myself as someone who is creative and inventive;" 10 items; $M=$ 3.86, $S D=.65, \alpha=.82$ ), conscientiousness (e.g., "I see myself as someone who keeps working until things are done;" 9 items; $M=3.43, S D=.68, \alpha=.80$ ), agreeableness (e.g., "I see myself as 
someone who is the kind of person almost everyone likes;" 8 items; $M=3.63, S D=.66, \alpha=.72$ ), and extraversion (e.g., "I see myself as someone who is outgoing, sociable;" 8 items; $M=3.23$, $S D=.83, \alpha=.85)$

\subsubsection{Relationship Contingent Self-esteem}

Participants indicated the extent to which their self-esteem fluctuates as a function of the quality of their relationships on items such as "My feelings of self-worth are based on how well things are going in my relationship" (Knee, Canevello, Bush, \& Cook, 2008). Participants in relationships responded regarding their current romantic partners, while those who were single responded according to their past relationships. Participants responded to 11 items on a scale from 1 (not at all like me) to 5 (very much like me), $M=3.34, S D=.78, \alpha=.87$.

\subsubsection{Social Goals}

I assessed convergent and discriminant validity of the Fear of Being Single scale by examining associations with social motivations in close relationships more generally. Participants reported their approach and avoidance goals when it comes to close relationships (Elliot, Gable, \& Mapes, 2006). On a scale from 1 (not at all true of me) to 7 (very true of me), participants indicated their social approach goals (e.g., "I am trying to enhance the bonding and intimacy in my close relationships;" 4 items; $M=5.39, S D=1.36, \alpha=.92$ ) and social avoidance goals (e.g., "I am trying to make sure that nothing bad happens to my close relationships;" 4 items; $M=5.18, S D=1.27, \alpha=.78)$.

\subsubsection{Need to Belong}

To assess general feelings of belonging, participants completed the need to belong scale (Leary, Kelly, Cottrell, \& Schreindorfer, 2007). On a scale from 1 (strongly disagree) to 5 
(strongly agree), participants responded to items such as, "I need to feel that there are people I can turn to in times of need;" 10 items; $M=3.38, S D=.67, \alpha=.80$.

\subsubsection{Depression}

Participants reported their frequency of 20 depressive symptoms over the prior week

(e.g., "I felt that I could not shake off the blues even with help from my family or friends"), from 1 (rarely or none of the time) to 4 (most or all of the time), $M=2.02, S D=.63, \alpha=.92$ (Radloff, 1977).

\subsubsection{Loneliness}

Participants' loneliness was assessed with the UCLA-Loneliness scale (Russell, Peplau, \& Cutrona, 1980). Participants responded to 20 items such as, "How often do you feel that you lack companionship?" from 1 (never) to 4 (always), $M=2.30, S D=.56, \alpha=.94$.

\subsubsection{Hurt Feelings Proneness}

Participants completed Leary \& Springer's (2001) hurt feelings proneness scale, responding to six items such as, "My feelings are easily hurt," from 1 (not at all characteristic of me) to 5 (extremely characteristic of $m e$ ), $M=3.27, S D=.79, \alpha=.78$.

\subsubsection{Rejection Sensitivity}

I assessed the extent to which participants were sensitive to rejection in general.

Rejection sensitivity is assessed by the expectancy of, and anxiety about, rejection during several hypothetical scenarios (e.g. "You approach a close friend to talk after doing or saying something that seriously upset him/her;” Downey \& Feldman, 1996). Participants' expectancy scores for each scenario are multiplied by their anxiety scores for each scenario, and the products for the 
nine scenarios are averaged to reflect a total rejection sensitivity score. Total scores may range from 1 (low rejection sensitivity) to 36 (high rejection sensitivity), $M=9.98, S D=4.53, \alpha=.79$.

\section{Study 2 Results}

The analyses proceeded in three stages. In the first stage, the Fear of Being Single scale was refined via factor analyses in Study 2A. In the second stage, the refined scale was crossvalidated via confirmatory factor analyses in Study 2B. In the third stage, Studies 2A and 2B were combined to assess the convergent and discriminant validity of the final scale.

\subsubsection{Refinement of the Initial Scale: Factor Analyses}

Factor analyses in Study 2A were used to select the best fitting scale items out of the original 17 items. A primary goal of the present research was to create an assessment tool that captures singlehood concerns of both males and females. To this end, factor analyses were conducted separately for males and females in Study 2A, selecting only items loading highly for both sexes. Factor analyses were conducted in parallel for men and women using principal components analysis with varimax rotation. After each round of factor analyses, items without a single loading greater than .50 were deleted, as were any items with substantial cross-loadings on a second factor (>.40). As can be seen in Table 2, this process yielded 8 items for males and 10 items for females, loading onto a single factor for each sex and accounting for more than half of the variance. The final scale was created by selecting only the items that loaded highly for both sexes, yielding a final scale of six items $(M=2.76, S D=1.07)$. The final scale included the items: "I feel it is close to being too late for me to find the love of my life," "I feel anxious when I think about being single forever," "I need to find a partner before I'm too old to have and raise children," "If I end up alone in life, I will probably feel like there is something wrong with me," “As I get older, it will get harder and harder to find someone," and "It scares me to think that 
Table 2. Factor loadings for males and females in Study 2A

\begin{tabular}{lcc}
\hline & Males & Females \\
\hline 1. I fear being alone when I am old. & - & .69 \\
2. I feel like I'm supposed to be in a serious romantic & - & .70 \\
relationship by now. & .85 & - \\
3. I sometimes feel as though everyone is in a & & .79 \\
relationship except for me. & .80 & .56 \\
4. It scares me to think that there might not be anyone & & .63 \\
out there for me. & - & .84 \\
5. People who never date or marry are kind of sad & .74 & .64 \\
6. I feel it is close to being too late for me to find the & & \\
love of my life. & .85 & .84 \\
7. I feel anxious when I think about being single & & \\
forever. & .73 & .01 \\
8. I need to find a partner before I'm too old to have and \\
raise children. \\
9. If I end up alone in life, I will probably feel like there \\
is something wrong with me. \\
12. I worry about how others will judge me if I am ever \\
single for too long. \\
13. If I never marry, I'll have a lonely life \\
14. As I get older, it will get harder and harder to find \\
someone.
\end{tabular}


there might not be anyone out there for me." Cronbach's alphas for males $(\alpha=.87)$, females ( $\alpha=$ $.86)$, and both sexes combined $(\alpha=.86)$ revealed substantial reliability of the reduced scale.

\subsubsection{Validation of the Final Scale: Confirmatory Factor Analyses}

In the second stage of analyses, the generalizability of the final scale was explored by determining whether the single factor structure derived in Study 2A provided an adequate fit to the data in Study 2B $(M=2.70, S D=.82, \alpha=.75)$. Confirmatory factor analyses were conducted with Amos 7 software. Multiple fit indices were examined to assess the adequacy of model fit, including $\chi^{2}$, the comparative fit index (CFI), and the root-mean-square error of approximation (RMSEA). Nonsignificant $\chi^{2}$ and CFI values greater than .90 indicate acceptable model fit (Bentler \& Bonett, 1980), and RMSEA values less than .05 indicate a close estimation of the population while values less than .08 indicate reasonable fit (Browne \& Cudeck, 1993).

Factor analyses were once again conducted separately for males and females, as well as for both sexes combined, to ensure that the scale adequately represented the concerns of both sexes. For both males and females separately, the single-factor 6-item Fear of Being Single scale evidenced excellent fit, $\chi^{2}(9) \mathrm{s}<8.61, n s$, CFIs $=1.00$, RMSEAs $=0$. The sample combining males and females also evidenced good model fit, $\chi^{2}(9)=12.99, n s, \mathrm{CFI}=.98, \mathrm{RMSEA}=.06$. Taken together, the confirmatory factor analysis results reveal that the reduced scale produced in Study 2A adequately fits the data from Study 2B.

\subsubsection{Convergent and Discriminant Validity}

In the third stage of analyses, Studies $2 \mathrm{~A}$ and $2 \mathrm{~B}$ were combined to create a larger sample $(N=448)$ with which to assess convergent and discriminant validity of the Fear of Being Single scale. Table 3 displays the zero-order correlations and multiple regressions predicting fear of being single. As expected, insecurity such as anxious attachment and neuroticism positively 
Table 3. Convergent and discriminant validity of Fear of Being Single scale (Studies 2A and 2B combined)

\begin{tabular}{|c|c|c|}
\hline & $\begin{array}{c}r \\
\text { (zero-order } \\
\text { correlation) }\end{array}$ & $\begin{array}{c}\beta \\
\text { (simultaneous } \\
\text { regression) }\end{array}$ \\
\hline \multicolumn{3}{|l|}{ Attachment Style } \\
\hline Anxious Attachment & $.51 * * *$ & $.52 * * *$ \\
\hline Avoidant Attachment & $.22 * * *$ & -.02 \\
\hline \multicolumn{3}{|l|}{ Personality } \\
\hline Neuroticism & $.28 * * *$ & $.24 * * *$ \\
\hline Extraversion & $-.12 *$ & -.03 \\
\hline Conscientiousness & $-.16^{* *}$ & -.05 \\
\hline Openness & $-.12 *$ & -.09 \\
\hline Agreeableness & $-.17 * *$ & -.04 \\
\hline \multicolumn{3}{|l|}{ Social Goals } \\
\hline Avoidance Social Goals & $.27 * * *$ & $.28 * * *$ \\
\hline Approach Social Goals & $.10^{*}$ & -.01 \\
\hline \multicolumn{3}{|l|}{ Interpersonal Sensitivity } \\
\hline Relationship Contingent Self-esteem & $.42 * * *$ & - \\
\hline Need to Belong & $.43 * * *$ & - \\
\hline Rejection Sensitivity & $.34 * * *$ & - \\
\hline Hurt Feelings Proneness & $.24 * * *$ & - \\
\hline Depression & $.42 * * *$ & - \\
\hline Loneliness & $.38 * * *$ & - \\
\hline
\end{tabular}

predicted fears about being single. Simultaneous regression of anxious and avoidant attachment revealed only an effect of anxious attachment. Simultaneous regression of personality traits revealed only an effect of neuroticism. Moreover, fear of being single was positively associated 
with avoidance or fear-based concerns, such as social avoidance goals. Discriminant validity was demonstrated, however, in that fear of being single was not associated with approach or rewardbased concerns, such as social approach goals. Finally, the Fear of Being Single scale was positively related to, although distinct from, measures of interpersonal sensitivity, such as relationship-contingent self-esteem, rejection sensitivity, hurt feelings proneness, depression, loneliness, and need to belong.

\section{Studies 2A and 2B Discussion}

Studies 2A and 2B produced a Fear of Being Single scale with sound statistical grounding. The preliminary scale of 17 items informed by responses in Study 1 was subjected to factor analyses on independent samples of participants. A final 6-item scale loading onto a single factor provided a good fit to the data. Importantly, this scale represented the concerns of both male and female participants. As expected, the Fear of Being Single scale was positively associated with anxious attachment, neuroticism, relationship-contingent self-esteem, and general interpersonal sensitivities. Furthermore, fear of being single was positively associated with social avoidance goals, but was not associated with social approach goals.

The results of these studies provide the groundwork for subsequent analyses exploring the consequences of fearing being single. A first analysis was conducted in Study $2 \mathrm{C}$ using data from the scale development studies. This analysis permitted a preliminary test of the hypothesis that fear of being single may promote settling for less in relationships. 


\section{Chapter 4}

\section{Settling for Less: Relationship Dependence}

One way in which individuals may be thought of as compromising their relationship standards (i.e., settling for less) is to remain committed to and invested in a poor quality relationship. Typically, dependence and commitment are considered to be positive and important aspects of relationship stability. Relationship dependence leads to greater commitment over time (Attridge, Berscheid, \& Sprecher, 1998; Wieselquist, Rusbult, Foster, \& Agnew, 1999). Furthermore, in a recent meta-analysis of longitudinal studies of romantic breakups, relational dependence was one of the strongest predictors of relationship stability (Le et al., 2010). However, to the extent that one's relationship is less healthy or satisfying, dependence and commitment may be less desirable. For instance, a study of women with abusive partners found that commitment was the key predictor of returning to the offending partner immediately after leaving a women's shelter, while satisfaction was not (Rusbult \& Martz, 1995).

For individuals who fear being single, nearly any relationship may promote dependence and commitment. Specifically, to the extent that those who fear being single are insecure about their ability to find and keep a partner for the long term, they may remain non-selectively committed to a relationship once they have one. Indeed, other studies have found that insecure individuals, such as those with anxious attachment, are more vulnerable to staying in relationships that do not satisfy their needs. For instance, whereas more secure individuals feel less committed to their romantic partners and are more likely to break up with their partners when the relationship does not meet their needs, anxiously attached individuals tend to maintain their relationship commitment despite their lack of need satisfaction (Slotter \& Finkel, 2009). In a longitudinal study of newly married couples over their first four years of marriage, couples 
with insecure partners were the most likely to be in stable, yet unhappy marriages (Davila \& Bradbury, 2001). In this way, those who fear being single may also settle for less by remaining committed to less satisfying relationships.

To explore the hypothesis that fear of being single would predict dependence in less satisfying relationships, I examined only participants in Studies 2A and 2B who reported being in a relationship. These participants provided additional data regarding their current relationship satisfaction and dependence. Specifically, I hypothesized that there would be a significant interaction between fear of being single and relationship satisfaction predicting relational dependence. While most participants should be dependent on relationships marked by high satisfaction, I expected that only those with stronger fear of being single would be dependent on less satisfying relationships.

\section{Study 2C Method}

\subsection{Participants \& Procedure}

The subsample of data in Study 2C was taken from Studies 2A and 2B. Specifically, Study 2C included all participants from Studies $2 \mathrm{~A}$ and $2 \mathrm{~B}$ currently involved in romantic relationships. There were 172 participants included in analyses ( 24 males, 147 females, 1 unidentified), ranging in age from 17 to 57 years old $(M=27.6, S D=9.2)$. Participants in this combined sample had been in their current relationships between 1 month and 40 years $(M=$ 39.9 months, $S D=57.3$ ). The following items were provided in addition to the items mentioned above, only to those participants who reported being in a romantic relationship. 


\subsection{Measures}

\subsubsection{Relationship Satisfaction}

Participants reported their satisfaction in their current relationship using the scale developed by Murray, Holmes, and Griffin (2000). Participants responded to four items on a scale from 1 (not at all true) to 6 (extremely true) such as, "I am extremely happy with my current relationship" $(M=4.50, S D=1.21, \alpha=.90)$.

\subsubsection{Relationship Dependence}

Participants also indicated how dependent they were on their current relationship (Murray, Holmes, MacDonald, \& Ellsworth, 1998). On a scale from 1 (not at all true) to 9 (completely true), participants responded to five items such as, "I feel that I need my partner a great deal," and "If I couldn't be in this relationship, I would lose an important part of myself" $(M=5.33, S D=1.93, \alpha=.85)$.

\section{Study $2 \mathrm{C}$ Results}

I conducted a hierarchical regression predicting relationship dependence, with fear of being single (standardized) and relationship satisfaction (standardized) entered in Step 1. To ensure that results were not attributable to systematic differences in length of the current relationship, relationship length was included as a covariate in Step 1. The interaction between fear of being single and relationship satisfaction was entered in Step 2. One outlier below 3 standard deviations from the mean of satisfaction was excluded from this analysis. Results revealed that the length of one's current relationship was a marginally significant, positive predictor of relationship dependence, $\beta=.13, p=.08$. Furthermore, both current relationship satisfaction, $\beta=.48, p<.001$, and fear of being single, $\beta=.23, p=.003$, were significant, positive predictors of relationship dependence. These main effects were qualified, however, by a 
significant interaction between fear of being single and relationship satisfaction, $\beta=-.18, p=.02$ (see Figure 1). Simple effects tests revealed that at high levels of relationship satisfaction, fear of being single did not predict relationship dependence, $\beta=.06, n s$. However, among those who were less satisfied in their relationships, stronger fear of being single predicted greater dependence on the relationship, $\beta=.37, p<.001$.

Figure 1. Dependence on a relationship as a function of relationship satisfaction and fear of being single in Study $2 \mathrm{C}$

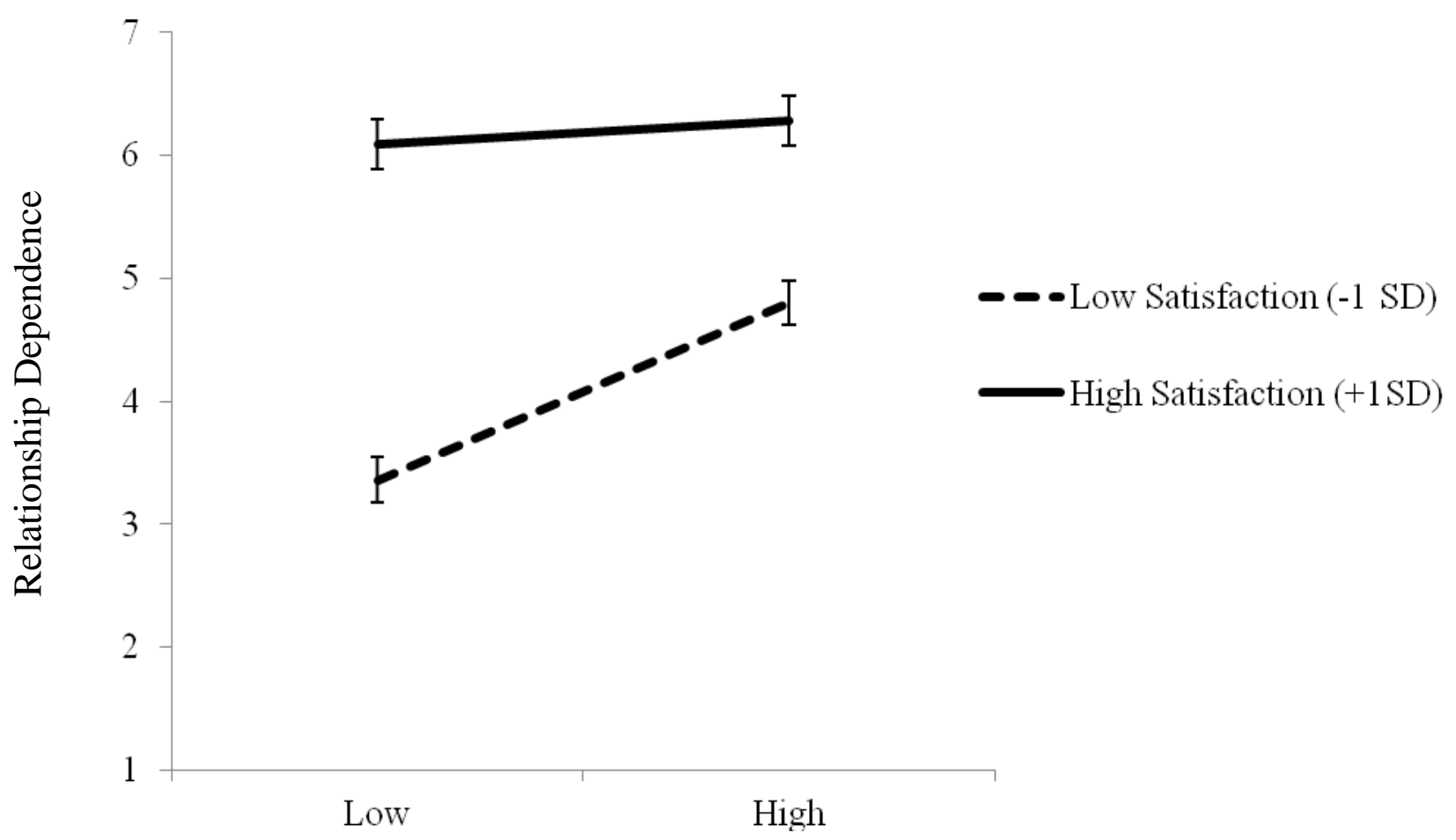

Fear of Being Single 
Follow-up analyses revealed that these effects cannot be accounted for by anxious attachment. I included the main effect of anxious attachment in Step 1, and to account for bias in the estimate of the fear of being single by relationship satisfaction interaction (Yzerbyt, Muller, \& Judd, 2004), I also included the interaction between anxious attachment and satisfaction in Step 2. First, analyses revealed that the interaction between fear of being single and satisfaction remained significant when controlling for the main effect and interaction of anxious attachment, $\beta=-.15, p=.04$. Furthermore, while the main effect of anxious attachment was a significant, positive predictor of dependence in the model, $\beta=.41, p<.001$, the interaction between anxious attachment and satisfaction was not significant, $\beta=.05, n s .{ }^{1}$ The effects also cannot be accounted for by neuroticism. The interaction between fear of being single and satisfaction held controlling for the main effect of neuroticism and the interaction between neuroticism and satisfaction, $\beta=-.24, p=.008$. While there was a significant main effect of neuroticism, $\beta=.22$, $p=.01$, the interaction between neuroticism and satisfaction was not significant, $\beta=-.08, n s$. Therefore, fear of being single accounted for variance in the association between relational satisfaction and dependence that could not be accounted for by more general insecurities such as anxious attachment and neuroticism.

\section{Study 2C Discussion}

Study $2 \mathrm{C}$ demonstrated that fear of being single predicts the extent to which relationship satisfaction promotes dependence. While relationships relatively high in satisfaction were associated with relatively high dependence regardless of individual differences in fear of being

1 Across all studies in this paper, follow-up analyses replacing fear of being single with anxious attachment as the moderator did not produce a significant interaction with anxious attachment, highlighting the distinction between anxious attachment and fear of being single. 
single, those who were afraid of being single reported being relatively dependent even on relationships they found less satisfying. Moreover, the present findings hold above and beyond the effects of anxious attachment and neuroticism. This suggests that fear of being single plays a unique role in the maintenance of unsatisfying relationships beyond insecurity-related constructs that are typically examined in the relationship literature. Fear of being single is a unique predictor of settling for less in one's relationship. 


\section{Chapter 5}

\section{Settling for Less: Dating Standards}

Given that those who fear being single may feel they desperately want or need a relationship, a strategy for maximizing their chances of starting a relationship could be to set lower standards when it comes to choosing a partner. People tend to have schemas, or cognitive expectancies, of what they consider to be ideal in a romantic partner on factors such as responsiveness and intimacy potential, physical attractiveness, and status/resources (Fletcher \& Simpson, 2000; Fletcher et al., 1999). Being willing to settle for lower quality mates would increase the pool of acceptable dating candidates and thus reduce the risk of ending up alone. In this sense, setting lower standards may provide psychological comfort, reassuring those who fear being single that they will not be single for long. Lowering their standards for a dating partner may therefore help ease people's fears about being single.

On the other hand, lowering standards may not provide psychological comfort about being single. The most commonly cited fear of singlehood in Study 1 was the risk of missing out on companionship and loving experiences. In other words, an important aspect of the fear of being single is a desire for a high quality relationship. Therefore, regardless of whether or not those who fear being single actually settle for lower quality partners, they may not be open to admitting this to themselves. It may be threatening to acknowledge holding low standards, out of fear that one may not find a quality relationship. Indeed, Tolmacz (2004) found that anxiously attached individuals were less willing to compromise their ideal mate standards.

It is unclear, therefore, whether the insecurity of fear of being single would prompt individuals to set lower or higher standards for a mate. The purpose of Studies 3A and 3B was to explore whether or not those who fear being single tend to report lower standards for a mate. 
Studies 3A and 3B were correlational studies in which participants reported their fear of being single and their standards for a dating partner.

\section{Study 3 A Method}

\subsection{Participants \& Procedure}

Participants were recruited online through Amazon.com's Mechanical Turk (www.mturk.com). A total of 254 individuals completed the survey. However, 8 individuals were excluded because of response sets according to an algorithm applied to reverse-coded items. There remained 246 participants (161 females, 84 males, 1 unidentified), 88 single and 158 in relationships. Participants ranged in age from 18 to 78 years old $(M=31.8, S D=11.9)$. While 218 participants identified as heterosexual, 28 identified otherwise (6 homosexual, 17 bisexual, 3 undecided/questioning, 1 other, and 1 unidentified). Participants completed the following measures in the order presented.

\subsection{Measures}

\subsubsection{Fear of Being Single}

Participants first completed the six item Fear of Being Single scale $(M=2.77, S D=1.09$, $\alpha=.83)$.

\subsubsection{Attachment Style}

Attachment style was assessed using the ASQ (Feeney et al., 1994). The $\alpha$ reliability of anxious attachment was $.88(M=3.18, S D=.85)$ and avoidant attachment was $.86(M=3.38, S D$ $=.68)$. 


\subsubsection{Ideal Partner Standards}

To gauge participants' standards for a romantic partner, participants were provided a series of hypothetical traits on a measure adapted from Buss and Shackelford (2008), and were asked to indicate, "In a romantic partner, how important are the following characteristics?" Participants responded on a scale from -2 (undesirable $-a$ "deal breaker") to +2 (indispensible - a "must have"). Traits were aggregated to form assessments of the importance of physical attractiveness (e.g., physically attractive, good looking, sexually appealing, physically fit, and good health; $M=.96, S D=.50, \alpha=.81$ ), resources (e.g., high income, good earning capacity, and good financial prospect; $M=.40, S D=.67, \alpha=.84$ ), good parenting potential (e.g., desire for home and children, good cook and housekeeper, priorities of raising children well, fond of children, and likes children; $M=.85, S D=.78, \alpha=.86$ ), and good partner potential (e.g., priorities of being a loving partner, devoted to you, loyal, mutual attraction/love, kind and understanding, emotional stability and maturity, pleasing disposition/personality, and dependable character; $M=1.51, S D=.47, \alpha=.88)$.

\section{Study 3A Results}

Correlations between fear of being single and dating standards in each domain of physical attractiveness, resources, good parent, and good partner are presented in Table 4. The first column in Table 4 presents zero-order correlations, and the second column presents partial correlations controlling for anxious attachment. ${ }^{2}$ When it comes to standards for attractiveness, resources, and being a good partner, the zero-order correlations with fear of being single were

2 In Studies 3A and 3B, all correlations remain the same when controlling for both anxious and avoidant attachment. However, since Study 2 suggests that fear of being single more closely maps onto anxious attachment, and not avoidant attachment, I report only the results controlling for anxious attachment here. 
not significant. However, fear of being single was significantly, positively correlated with standards for being a good parent. Moreover, the effects held controlling for anxious attachment, with the exception of standards for attractiveness, which were positively correlated with fear of being single when accounting for anxious attachment. Furthermore, there were no significant interactions for all four standards domains with participant age, sex, relationship status, or sexual orientation (comparing heterosexual with all non-heterosexual categories combined).

Table 4. Correlations between fear of being single and dating standards in Study 3A

\begin{tabular}{lcc}
\hline Standards & Zero-order correlations & $\begin{array}{c}\text { Correlations controlling } \\
\text { for anxious attachment }\end{array}$ \\
\hline Attractiveness & .03 & $.15^{*}$ \\
Resources & .03 & .10 \\
Good Parent & $.22 * * *$ & $.22 * * *$ \\
Good Partner & .06 & .06 \\
\hline Note. $* * * p<.001, * p<.05$ & &
\end{tabular}

\section{Study 3A Discussion}

The results of Study 3A suggest that self-reported dating standards are not lower for those who fear being single. In fact, while fear of being single was not typically significantly associated with dating standards, in cases where it was, it was actually associated with higher standards. Specifically, those who fear being single reported higher standards for a partner who would be a good parent, and higher standards for a partner who was attractive (when accounting for the effects of anxious attachment). Overall, then, the results of the present study appear to demonstrate that those who fear being single do not indicate a willingness to settle for less when it comes to their ideal romantic partner. 
One limitation of Study 3A is that participants were asked only about their desired mate characteristics. It is possible that people's dream partner is not affected by their anxieties about being single, but perhaps the extent to which they are willing to accept deviations from their ideal partner (i.e., compromise their standards) is driven by fear of being single. Participants in Study 3B were therefore asked not only about their desired partner standards, but also the minimum for which they would be willing to settle in order to date somebody. I hypothesized that fear of being single would not generally predict ideal partner standards (replicating the results of Study 3A), but explored whether fear of being single would predict lower minimum partner standards, such that those who fear being single may report being willing to settle for less in a romantic partner.

\section{$4 \quad$ Study 3B Method}

\subsection{Participants \& Procedure}

Participants were once again recruited online through Mechanical Turk. In accordance with other hypotheses being explored in these data, individuals were required to be single at the time of the study to be eligible to participate. One hundred fifty-nine participants completed the survey. However, 7 participants were excluded because they were in serious romantic relationships, and 11 were excluded because of response sets. There remained 141 participants (86 female, 55 male) included in analyses. Participants ranged in age from 18 to 78 years old ( $M$ $=30.00, S D=10.41)$. Participants completed the following measures online, with all participants evaluating ideal partner standards before minimum partner standards.

\subsection{Measures}

\subsubsection{Fear of Being Single}

The Fear of Being Single scale had an $\alpha$ of $.87(M=2.93, S D=1.08)$. 


\subsubsection{Attachment Style}

Using the ASQ (Feeney et al., 1994) to assess attachment style, the $\alpha$ reliability of anxious attachment was $.91(M=3.39, S D=.88)$ and avoidant attachment was $.85(M=3.61, S D$ $=.64)$.

\subsubsection{Ideal Partner Standards}

To ensure that null effects for ideal partner standards were not due to the specific instrument used, I employed a different scale in Study 3B than in 3A. To gauge standards for an ideal partner, participants were provided a series of traits, and were asked to indicate the percentile score that would be most desirable for that trait (e.g., Regan, 1998). In other words, above what percentage of all other same-sex individuals would one's perfect partner fall on a given characteristic? Responses were provided in percentile format, ranging from $0 \%$ to $100 \%$. Traits were aggregated to form assessments of ideal standards for physical attractiveness (e.g., physically attractive, sexy, and healthy; $M=69.63 \%, S D=17.71, \alpha=.76$ ), resources (e.g., wealthy, powerful, good earning capacity, and has material possessions; $M=48.02 \%, S D=$ $18.99, \alpha=.82$ ), good parenting potential (e.g., wants children; $M=47.89 \%, S D=35.84$ ), and good partner potential (e.g., attentive to partner's needs, easy going, friendly, and good sense of humor; $M=74.13 \%, S D=15.69, \alpha=.83)$.

\subsubsection{Minimum Partner Standards}

After evaluating ideal partner standards, participants were provided with a list of the same traits, and were asked to indicate the minimum percentile score that they would find acceptable when considering a potential romantic partner. Responses were again provided in percentile format, ranging from $0 \%$ to $100 \%$. Participants rated the extent to which they would settle on physical attractiveness $(M=48.50 \%, S D=20.25, \alpha=.83)$, resources $(M=31.42 \%, S D$ 
$=19.35, \alpha=.88)$, parenting potential $(M=31.86 \%, S D=33.59$, single item thus no $\alpha)$, and good partner potential $(M=53.16 \%, S D=19.28, \alpha=.89)$.

\section{Study 3B Results}

Correlations between fear of being single and dating standards are presented in Table 5.

The first column displays correlations with ideal standards for attractiveness, resources, good parent potential, and good partner potential, while the second column displays correlations with minimum standards. The results for ideal standards replicate those of Study 3A, such that fear of being single did not significantly predict standards for attractiveness, resources, nor good partner potential, and predicted marginally higher standards for good parenting potential. Moreover, participants' minimum standards were not predicted by fear of being single, with the exception of good parenting potential which was again positively predicted by fear of being single.

Columns 3 and 4 in Table 5 display the correlations controlling for anxious attachment. All correlations held controlling for anxious attachment. Furthermore, there were no significant

Table 5. Correlations with fear of being single in Study 3B

\begin{tabular}{lcccc}
\hline & \multicolumn{2}{c}{ Zero-order Correlations } & \multicolumn{2}{c}{ Controlling for Anxious Attachment } \\
\cline { 2 - 5 } Standards & $\begin{array}{c}\text { Ideal } \\
\text { Standards }\end{array}$ & $\begin{array}{c}\text { Minimum } \\
\text { Standards }\end{array}$ & $\begin{array}{c}\text { Ideal } \\
\text { Standards }\end{array}$ & $\begin{array}{c}\text { Minimum } \\
\text { Standards }\end{array}$ \\
\hline Attractiveness & -.03 & -.02 & .10 & .09 \\
Resources & .05 & .03 & .04 & .04 \\
Good Parent & $.14+$ & $.17^{*}$ & $.15+$ & $.18^{*}$ \\
Good Partner & .09 & .03 & .00 & .01 \\
\hline
\end{tabular}

Note. $* p<.05,+p<.10$ 
interactions with participant age or sexual orientation, but there were mixed results for interactions with participant sex. Sex interacted with fear of being single to predict ideal standards for good parenting, $\beta=-.20, p=.05$, such that fear of being single predicted higher ideal standards for parenting potential among women, $\beta=.27, p=.01$, but not among men, $\beta=-$ $.08, n s$. Sex also interacted with fear of being single to predict ideal standards for good partner potential, $\beta=-.26, p=.01$, such that women reported higher ideal standards for a good partner with greater fear of being single, $\beta=.24, p=.02$, while men did not, $\beta=-.20$, ns. There were no other interactions with ideal standards, and no interactions with minimum standards.

\section{Study 3B Discussion}

The results of Study 3B replicate the finding that fear of being single does not predict lower self-reported dating standards. Whether participants were asked about their standards for an ideal partner or the bare minimum for which they would settle in a dating partner, fear of being single was consistently unrelated to dating standards. The one exception, which replicated the results of Study $3 \mathrm{~A}$, was the extent to which participants desired a partner who wanted children. Those with stronger fear of being single reported higher ideal standards and higher minimum standards for parenting potential compared to those with weaker fear of being single. This finding suggests that having children and a family is an important component of the fear of being single. Indeed, participants in Study 1 noted in their open-ended responses about being single that missing out on having children was a relevant concern. Furthermore, an item in the Fear of Being Single scale taps into fears about not having and raising children. It appears, then, that when considering a hypothetical mate, the prospect of dating someone who does not want children may be more of a "dealbreaker" for those with stronger fear of being single, at least at the level of abstract standards. Furthermore, the effect in Study 3B (although not Study 3A) 
revealed a moderation by participant sex, such that women who feared being single held higher standards for an ideal partner with parenting and partner potential than did men. While effects that do not replicate across studies should be interpreted cautiously, it is possible that such sex differences reflect concerns over parental investment. Women invest a greater amount of reproductive time and energy per child than men, which may make them more selective and concerned with paternal support (e.g., Geary, 2000). 


\section{Chapter 6}

\section{Settling for Less: Relationship Initiation}

Although participants did not report a willingness to lower their standards when choosing a mate, self-reported standards do not always predict behavior. For instance, speed-dating research has shown that what people claim they seek in a partner before a dating event is not necessarily what they select during their real dating interactions (Eastwick \& Finkel, 2008). Research on the hot-cold empathy gap suggests that individuals may not accurately predict their future behavior because they do not take into account the "hot" emotions they will be experiencing in the moment (e.g., Loewenstein, 1996). In this way, those who fear being single may state they would not settle for a lower quality partner, but may behave differently when presented with an actual dating prospect. Therefore, the purpose of Study 4 was to explore whether those who fear being single express romantic interest in actual lower quality dating prospects.

Past research has suggested that desire for a romantic partner can motivate settling for less during mate selection. McClure, Lydon, Baccus, and Baldwin (2010) found that anxiously attached individuals had a bias for expressing romantic interest in everyone they met at a speed dating event, reflecting an unselective mate initiation process. Similarly reflecting lower standards during mate selection, anxiously attached individuals were more likely to be attracted to targets who did not appear sensitive and who were not smiling (Wood \& Brumbaugh, 2009). It is possible, therefore, that insecurity based in the fear of being single will predict being less selective during relationship initiation.

To examine whether those who fear being single are willing to settle for lower quality dating partners, participants in Study 4 indicated their desire to date either more or less desirable 
dating targets in an online dating scenario. Desirability was manipulated in the present study by varying the degree to which targets appeared to be high in partner responsiveness. The extent to which partners have the potential for mutual responsiveness to each other's needs, and the potential for close, intimate connection is an important marker of relationship quality (Maisel \& Gable, 2009; Reis, Clark, \& Holmes, 2004; Spielmann, MacDonald, \& Tackett, 2012). Indeed, intimacy and closeness stemming from partner responsiveness are key to creating rewarding close relationships (Laurenceau, Feldman Barrett, \& Pietromonaco, 1998; Laurenceau \& Kleinman, 2006). A partner is considered responsive if $\mathrm{s} / \mathrm{he}$ "attend[s] to and react[s] supportively to central, core defining features of the [partner's] self" (Reis et al., 2004, p. 203). Responsive partners are therefore caring, understanding, and validating. The relationship literature extols the importance of partner responsiveness for relationship satisfaction, commitment, and longevity. Those who perceive their relationship partners as responsive feel more intimate, more satisfied, and more committed to their relationships (Karney \& Bradbury, 1995; Reis et al., 2004). Therefore, to the extent that individuals would be willing to compromise their standards for a responsive partner may particularly demonstrate a willingness to settle for less. For this reason, the primary focus in Study 4 was on the extent to which those who fear being single were willing to compromise on factors of responsiveness and emotional satisfaction. After reading the target's profile, consisting of a photo and self-description, participants rated their romantic interest, assessed as their degree of interest in the target's personality and desire to go on a date with the target. I hypothesized that those with stronger fear of being single would express greater romantic interest in the unresponsive targets than would their less fearful counterparts. Furthermore, it is possible that participants would express romantic interest in lower quality targets due to motivated perceptions that they could form a successful relationship with a lower quality target. For instance, perhaps those who fear being single are more likely to 
turns faults into virtues (e.g., Murray \& Holmes, 1993) and feel that a partner's flaws are not cause for upset. To account for this possibility, participants evaluated the extent to which they anticipated being able to form a successful, lasting relationship with the target.

\section{Study 4 Method}

\subsection{Participants \& Procedure}

Participants were single, heterosexual, undergraduate females who participated for course credit. This study included only heterosexual females for simplicity of preparation of dating profiles. Ninety-nine participants began the study, but 11 participants were excluded: One participant was excluded because she reported being in a serious relationship, three participants were excluded because they left the majority of questions blank, one participant experienced language difficulties, one participant left the study for an extended period of time to take a phone call, and five participants revealed response sets. There remained 88 female participants in the analyses. ${ }^{3}$ These participants ranged in age from 17 to 32 years old $(M=18.73, S D=2.06)$. Eighty-four participants indicated they were single, and four reported they were casually dating.

Participants first completed questionnaires assessing fear of being single and attachment style. Next, under the cover story that the study was about "personality and evaluations of online dating profiles," participants viewed an ostensibly real online dating profile of a man from the Toronto area. The dating profile in each case included an attractive male photo, as well as a written profile that depicted the man as either high or low in partner responsiveness. Following the profile, participants evaluated the target on attractiveness and responsiveness, and indicated their romantic interest in the target. Participants were then probed for suspicion, thanked and

\footnotetext{
3 This sample of participants was included in Study 5 of Spielmann, Maxwell, MacDonald, and Baratta (in press). However, the specific associations discussed in the present research have not been presented elsewhere.
} 
debriefed.

\subsection{Measures}

\subsubsection{Fear of Being Single}

Participants completed the Fear of Being Single scale $(M=2.69, S D=.99, \alpha=.84)$.

\subsubsection{Attachment Style}

Attachment style was again assessed using the ASQ (Feeney et al., 1994). Anxious attachment had a reliability of $.90(M=3.22, S D=.91)$ and avoidant attachment had a reliability of $.84(M=3.28, S D=.66)$.

\subsubsection{Dating Profiles}

All profiles included one of two counterbalanced attractive male photos, pilot tested for equivalency in physical attractiveness, $F(1,21)=2.51, p=.13$. Each photo was accompanied by an "About Me" section that the males had supposedly written themselves. These biographies differed in the extent to which the male appeared responsive. Pilot testing revealed a significant difference in perceived caring and responsiveness between the two profiles, $F(1,20)=303.60, p$ $<.001$. Those in the High Responsiveness Target condition read a profile where the target made statements such as, “When I'm dating someone, I really care about putting in the effort and making it work. For me, that means paying attention to my girlfriend and getting to know who she really is as a person," and "I figure the most important thing is that we're there for each other, no b.s." Those in the Low Responsiveness Target condition read a profile with statements such as, "I love what I do, so I need someone who respects that and is willing to take the back seat when necessary," and "I like to keep conversations light and not too serious when they're not work-related, and I most prefer situations that are easy and problem-free." 


\subsubsection{Responsiveness}

As a manipulation check, participants rated the responsiveness of the male target. The manipulation check was an aggregate of the questions, "How caring is this individual?" "How considerate is this individual?" and "How responsive does this individual seem towards his future partner's needs?" rated on a scale from 1 (not at all) to 5 (extremely); $M=3.04, S D=$ $1.29, \alpha=.93$.

\subsubsection{Attractiveness}

To confirm that the attractiveness of the target photos was not affected by responsiveness condition or fear of being single, participants rated the target male on the following items, on a scale from 1 (not at all) to 5 (extremely): attractive, handsome, and cute. Items were aggregated to form a single attractiveness rating; $M=3.37, S D=.78, \alpha=.85$.

\subsubsection{Romantic Interest}

Participants evaluated the extent to which they were romantically interested in the target males. Romantic interest was assessed with items tapping into expectations that one would "click" romantically with the target, interest in learning more about the target, the target's desirability as a romantic partner, and the extent to which participants desired to go on a date with the target. Ratings were made on a scale from 1 (not at all) to 5 (extremely); $\alpha$ of the four items was $.88, M=2.55, S D=.94$.

\subsubsection{Anticipated Romantic Success}

I gauged participants' anticipated romantic success with the target using the item, "How successfully do you think you and this individual could form a lasting romantic relationship?" Participants indicated their anticipated relationship success on a scale from 1 (not at all) to 5 (extremely); $M=2.22, S D=1.00$. 


\section{Study 4 Results}

\subsection{Manipulation Checks}

\subsubsection{Perceived Responsiveness}

To confirm that responsiveness condition influenced participants' perceptions of the targets' responsiveness, a hierarchical regression analysis was conducted for perceived responsiveness. Condition (dummy coded: $0=$ low responsiveness condition, $1=$ high responsiveness condition), and fear of being single (standardized) were entered in Step 1. The interaction between responsiveness condition and fear of being single was entered in Step 2. The analysis revealed a main effect of responsiveness condition, $\beta=.87, p<.001$, such that those who read the high responsiveness profile rated the target as significantly more responsive than those who read the low responsiveness profile. There was no effect of fear of being single, $\beta=$ $.03, n s$. Moreover, the interaction between condition and fear of being single was not significant, $\beta=-.11, n s$

\subsubsection{Attractiveness}

The same regression analysis as above was conducted on ratings of target attractiveness. Neither responsiveness condition, $\beta=.08, n s$, nor fear of being single, $\beta=.11$, ns, were significant predictors of attractiveness ratings, nor was the interaction between condition and fear of being single, $\beta=-.06, n s$.

\subsection{Romantic Interest}

To explore my primary hypothesis that those who fear being single may express romantic interest in lower quality dating targets, romantic interest in the target was regressed onto responsiveness condition and fear of being single in Step 1, and their interaction in Step 2. Responsiveness condition was a significant predictor of romantic interest, $\beta=.32, p=.002$, such 
Figure 2. Romantic interest as a function of target responsiveness and fear of being single in Study 4

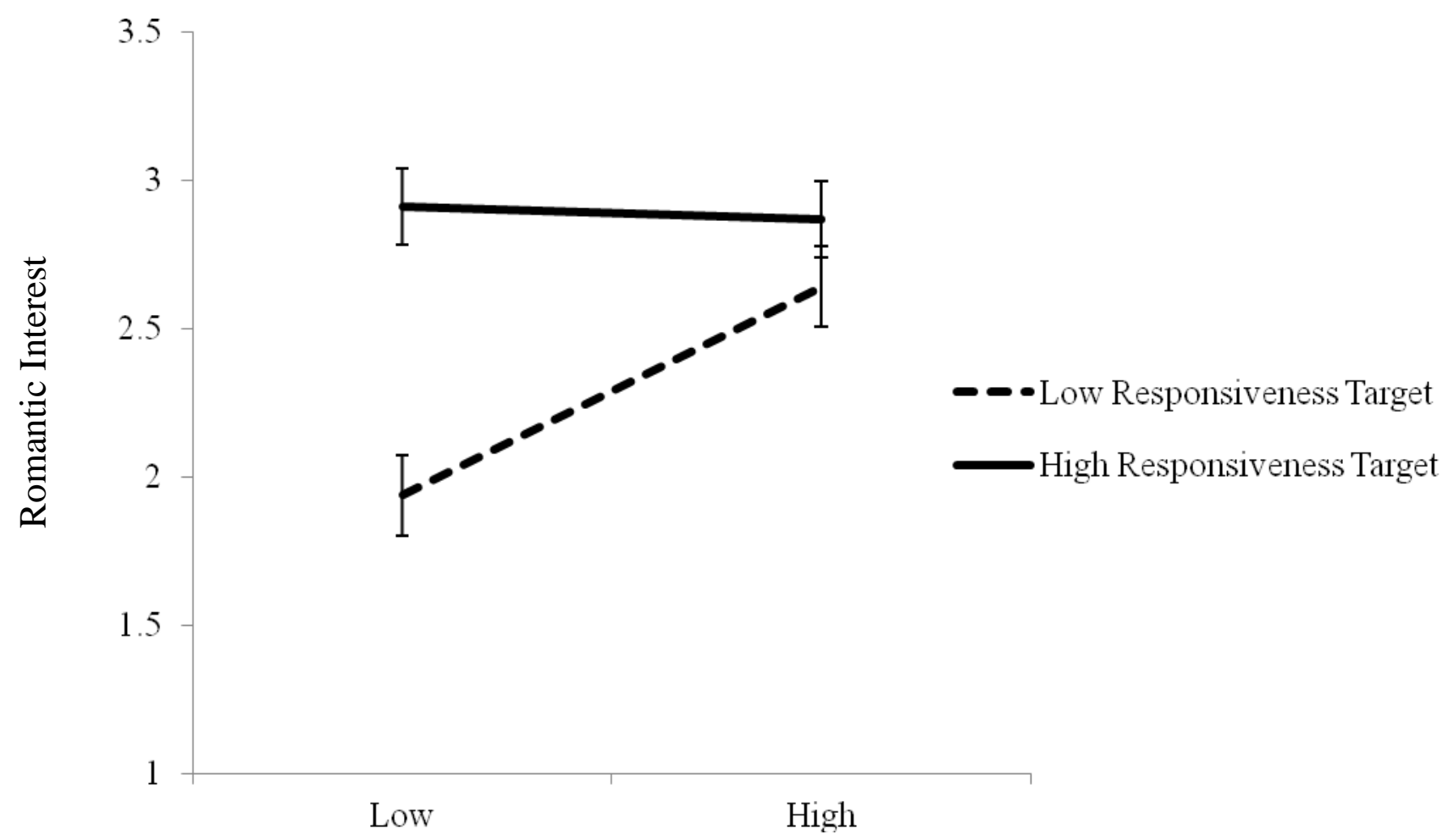

Fear of Being Single

that those who read the high responsiveness profile were more romantically interested in the target than those who read the low responsiveness profile. There was no main effect of fear of being single, although the data reflect a non-significant positive trend, $\beta=.17, p=.11$. However, the interaction between responsiveness condition and fear of being single was significant, $\beta=$ $.29, p=.05$ (see Figure 2). Simple effects tests were conducted to explore the effects of fear of being single at $\pm 1 \mathrm{SD}$ within each condition. Within the high responsiveness condition, fear of being single was not a significant predictor of romantic interest, $\beta=-.02$, $n s$. Within the low responsiveness condition, fear of being single was a significant predictor of romantic interest, $\beta$ $=.37, p=.01$, such that those with stronger fear of being single were more romantically 
interested in the low responsiveness target than those with weaker fear of being single.

Furthermore, while those with weaker fear of being single were more romantically interested in the high responsiveness target than the low responsiveness target, $\beta=.52, p<.001$, those with stronger fear of being single showed no difference in preference between the high responsiveness and low responsiveness targets, $\beta=.12, n s$. This interaction was not further moderated by participant age, $\beta=-.009, n s$.

Of particular importance in distinguishing the fear of being single construct from other relational insecurities, all effects of fear of being single on romantic interest remained significant when accounting for anxious attachment, which was not a significant predictor of romantic interest in the model, $\beta=-.12$, ns. Furthermore, the fear of being single by responsiveness condition interaction remained significant when controlling for bias due to the interaction between anxious attachment and responsiveness condition, $\beta=-.46, p=.01$ (Yzerbyt et al., 2004). Importantly, the interaction between anxious attachment and responsiveness condition was not significant, $\beta=.29$, ns.

\subsection{Anticipated Romantic Success}

To rule out the possibility that those who fear being single are more likely to believe that they could form a successful lasting relationship with less desirable targets, anticipated romantic success was regressed onto responsiveness condition, fear of being single, and their interaction. Responsiveness condition was a significant predictor of anticipated romantic success, $\beta=.42, p$ $<.001$, such that people expected to be able to form a more successful lasting relationship with the high responsiveness target than the low responsiveness target. However, there was no main effect of fear of being single, $\beta=.12, n s$, nor was there a significant interaction, $\beta=-.03$, ns. 


\section{Study 4 Discussion}

The results of Study 4 suggest that those who fear being single may select dating partners in a relatively non-discriminating manner. Despite accurate recognition of the responsiveness of targets, and despite lower expectations of forming a successful, lasting relationship with the less responsive target, those with stronger fear of being single nonetheless expressed greater romantic interest in the low responsiveness target. Specifically, those who feared being single were not only more romantically interested in the less responsive target compared to their less fearful counterparts, but they were also relatively equally interested in both the responsive and unresponsive targets. These findings suggest that romantic interest on the part of those who fear being single are not informed by perceptions of responsiveness or desirability in the same way as they are for less fearful individuals. As a consequence, women who fear being single may be prone to being equally drawn to both responsive and unresponsive partners.

Although Study 4 supported the main hypothesis, there were a number of limitations that I attempted to address in a follow-up study. First, Study 4 included only female participants. Study 5 was therefore designed to include both male and female participants, to examine whether the effect of fear of being single on romantic interest in lower quality dating partners can be extended to both sexes. Another important limitation of Study 4 was that, although people seemed willing to compromise on responsiveness if they feared being single, I do not have evidence of willingness to compromise more generally. That is, there could be something unique about responsiveness such that people are willing to compromise on it, rather than a more general phenomenon of being willing to settle for less in order to enter a relationship. For this reason, Study 5 included manipulations of responsiveness as well as physical attractiveness.

Finally, participants in Study 4 evaluated romantic interest largely in terms of the target's general desirability and romantic appeal. For instance, only one item tapped into explicit desire 
to go on a date with the target, while other items assessed general interest in learning more about and getting along with the target. To further clarify that those who fear being single are willing to initiate new relationships with lower quality partners, participants in Study 5 reported their explicit desires for having sex, going on a date, and forming a long-term relationship with each target. This more explicit measure of romantic interest provides a powerful test of the effect of fear of being single on willingness to settle, as it taps into desires that may promote actual initiation of lower quality relationships.

Study 5 was designed as an extension to Study 4, following a similar paradigm with similar hypotheses. As mentioned above, Study 5 included both male and female participants and manipulated target responsiveness as well as physical attractiveness. Moreover, romantic interest was assessed with items more explicitly tapping into desire to initiate a romantic liaison with the target. I again hypothesized that those with stronger fear of being single would express greater romantic interest in less responsive and less attractive dating targets.

\section{$4 \quad$ Study 5 Method}

\subsection{Participants \& Procedure}

Participants were single, heterosexual males and females recruited from Mechanical Turk. A total of 252 participants completed the survey, with 214 (91 males, 123 females) included in analyses. Two participants were excluded for being in a romantic relationship, one reported being neither heterosexual nor bisexual, and 35 revealed response sets. Participants ranged in age from 18 to 68 years old $(M=29.5, S D=10.8)$.

The procedure was similar to that of Study 4, such that participants completed measures of fear of being single and anxious attachment, and then evaluated an ostensibly real online dating profile. In addition to the manipulation of responsiveness used in Study 4, however, the 
targets in the present study also varied in attractiveness, with participants viewing either a highly attractive or less attractive photograph in conjunction with the profile. To ensure that effects were not due to the particular photos I selected, participants were randomly assigned to view one of two attractive or unattractive photos.

\subsection{Measures}

\subsubsection{Fear of Being Single}

Participants first completed the Fear of Being Single scale $(M=2.79, S D=1.04, \alpha=.85)$.

\subsubsection{Attachment Style}

Participants completed the anxious attachment $(\alpha=.90, M=3.20, S D=.90)$ and avoidant attachment $(\alpha=.86, M=3.46, S D=.69)$ subscales of the ASQ (Feeney et al., 1994).

\subsubsection{Attitudes toward Online Dating}

Online dating is sometimes considered as a less desirable means of meeting someone (e.g., Wildermuth, 2004). I therefore wanted to take into account participants' general attitudes toward online dating when assessing attitudes towards online dating targets. To gauge attitudes toward online dating, participants were asked about their perceptions of the ease of meeting someone online and the quality of partners available online. Participants responded on a scale from 1 (not at all) to 5 (very much) to the two items, "How easy do you think it would be to meet a romantic partner on an online dating website?" and "How likely is it you could meet a desirable, high quality dating partner on an online dating website?" These items were aggregated to form a measure of positive attitudes toward online dating, $r(213)=.58, p<.001(M=2.66$, $S D=.99)$. 


\subsubsection{Dating Profiles}

Target responsiveness was manipulated using the same profiles as in Study 4.

Furthermore, participants were randomly assigned to view either an attractive or unattractive photo in conjunction with the profile. Within the attractive and unattractive conditions, participants viewed one of two randomly assigned photos. Pilot tests revealed a significant difference in attractiveness between the attractive male photos $(M=3.01, S D=.15)$ and unattractive male photos $(M=1.40, S D=.08), F(1,21)=101.72, p<.001$, and between attractive female photos $(M=4.01, S D=.11)$ and unattractive female photos $(M=1.74, S D=$ $.11), F(1,24)=399.08, p<.001$.

\subsubsection{Responsiveness}

As a check of the responsiveness manipulation, after viewing the profile participants rated the extent to which the target was caring, considerate, and would be responsive to his/her partner's needs, on a scale from 1 (not at all) to 5 (extremely); $M=2.73, S D=1.31, \alpha=.96$.

\subsubsection{Attractiveness}

As a manipulation check of the attractiveness manipulation, participants rated the extent to which the target was attractive, cute, sexy, and handsome/beautiful (depending on target sex), on a scale from 1 (not at all) to 5 (extremely); $M=2.55, S D=1.05, \alpha=.94$.

\subsubsection{Romantic Interest}

Building on Study 4, romantic interest in the present study was assessed with items tapping into more explicit romantic desires. Specifically, as in Study 4, participants reported on a scale from 1 (not at all) to 5 (extremely) the extent to which they would like to go on a date with the target. However, participants additionally rated the extent to which they would like to have sex with the target and would like to form an exclusive relationship with the target. These three 
items were aggregated to form a single assessment of romantic interest reflecting relationship $\operatorname{approach}(M=1.95, S D=1.05, \alpha=.88)^{4}$

\subsubsection{Anticipated Romantic Success}

Once again, participants indicated the extent to which they expected they could successfully form a lasting romantic relationship with the target, on a scale from 1 (not at all) to 5 (extremely); $M=1.90, S D=1.06$.

\section{$5 \quad$ Study 5 Results}

\subsection{Attitudes toward Online Dating}

To explore whether positive attitudes toward online dating more generally affect people's perceptions of online dating targets, I examined the zero-order correlations between attitudes toward online dating and the dependent variables. The analysis revealed that the more positive attitudes participants held toward online dating in general, the more attractive they perceived the targets, $r(214)=.12, p=.08$, the more romantic interest they expressed toward the targets, $r(214)=.16, p=.02$, and the more they expected being able to form a lasting relationship with the target, $r(214)=.19, p=.006$. In other words, general attitudes toward online dating were associated with a number of the dependent variables of interest. As a consequence, all analyses below include attitudes toward online dating as a covariate.

4 The three items assessing interest in dating, sex, and long-term relationships loaded onto a single factor, suggesting that these items could not be parsed into short-term vs. long-term mating goals (e.g., Gangestad \& Simpson, 2000). 


\subsection{Manipulation Checks}

\subsubsection{Perceived Responsiveness}

To confirm that responsiveness condition influenced participants' perceptions of the targets' responsiveness, a hierarchical regression analysis was conducted for perceived responsiveness. Responsiveness condition $(0=$ low responsiveness, $1=$ high responsiveness $)$, attractiveness condition ( $0=$ unattractive, $1=$ attractive $)$, fear of being single (standardized), and online dating attitudes were entered in Step 1. All two-way interactions were entered in Step 2, and the three-way interaction was entered in Step 3. Online dating attitudes were included only in Step 1. The analysis revealed a main effect of responsiveness condition, $\beta=.80, p<.001$, such that those who read the high responsiveness profile rated the target as significantly more responsive than those who read the low responsiveness profile. There were no main effects of attractiveness condition, $\beta=.01, n s$, fear of being single, $\beta=.01, n s$, or online dating attitudes, $\beta$ $=.03, n s$. Moreover, neither the two-way nor three-way interactions were significant, all $\beta \mathrm{s}<$ $|.11|$

\subsubsection{Attractiveness}

The same regression analysis as above was conducted on ratings of target attractiveness. The analysis revealed a main effect of attractiveness condition, $\beta=.57, p<.001$, such that participants rated the attractive photos as significantly more attractive than the unattractive photos. Moreover, there was a main effect of responsiveness condition, $\beta=.18, p=.001$, such that high responsiveness targets were rated as more physically attractive than low responsiveness targets. As shown earlier, online dating attitudes were also a significant, positive predictor of attractiveness, $\beta=.12, p=.04$. There was no main effect of fear of being single, $\beta=-.04, n s$. Once again, none of the higher-order interactions was significant. 


\subsection{Romantic Interest}

As with the manipulation check analyses, romantic interest was regressed onto online dating attitudes, fear of being single, attractiveness and responsiveness conditions, and all twoand three-way interactions in separate steps. The analysis revealed a main effect of responsiveness condition, $\beta=.23, p<.001$, and attractiveness condition, $\beta=.41, p<.001$, such that participants were more romantically interested in the high responsiveness target and attractive target, respectively, than the low responsiveness and unattractive target, respectively. Online dating attitudes was also a significant, positive predictor of romantic interest, $\beta=.15, p=$ .01 . There was no main effect of fear of being single, $\beta=-.05, n s$.

Replicating the results of Study 4, there was a significant interaction at Level 2 between fear of being single and responsiveness condition, $\beta=-.17, p=.05$ (see Figure 3 ). The pattern of results replicated those from Study 4. Simple effects tests show that within the high

Figure 3. Romantic interest as a function of target responsiveness and fear of being single in Study 5

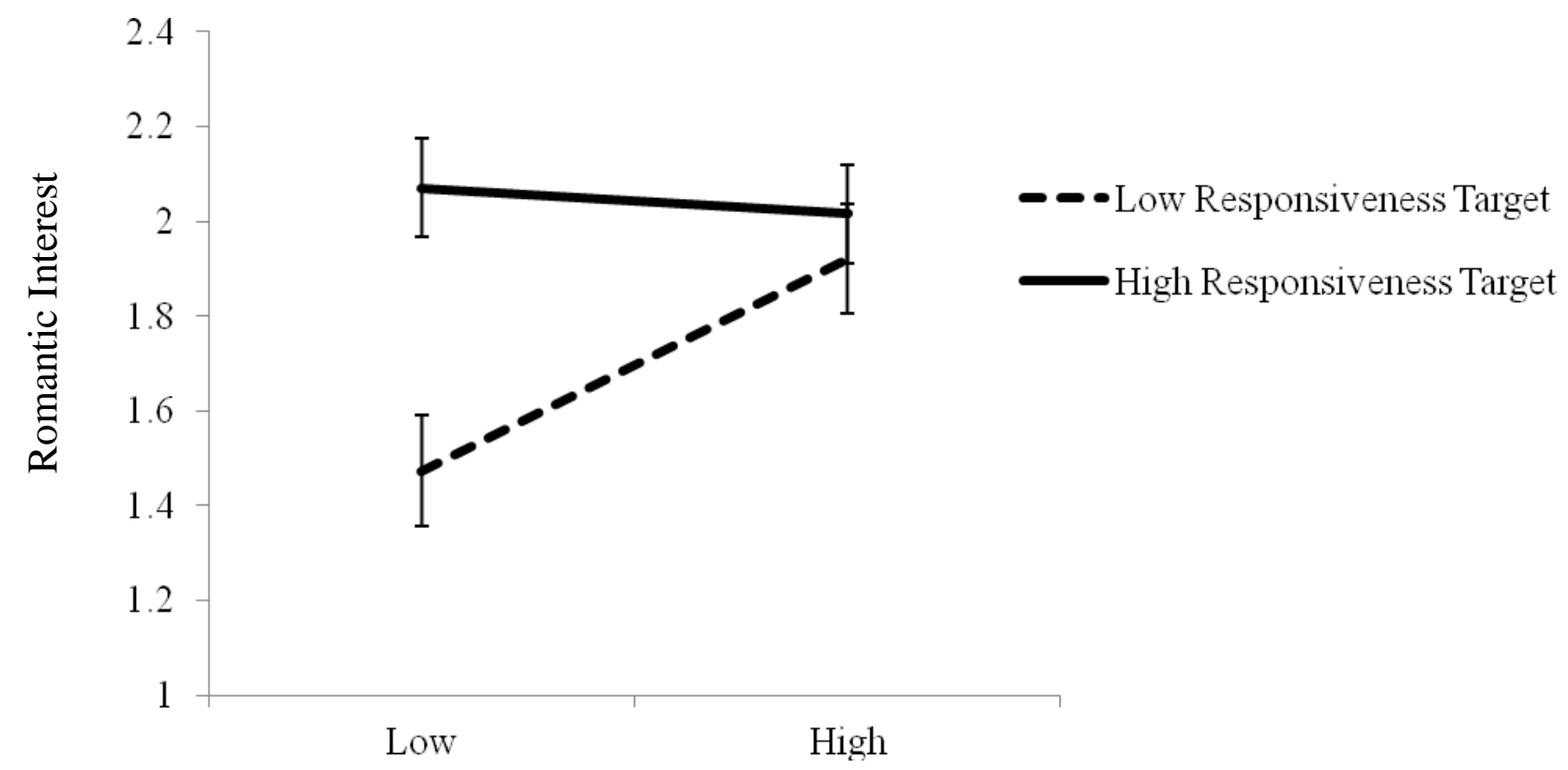


responsiveness condition, fear of being single was not a significant predictor of romantic interest, $\beta=-.03$, ns. However, within the low responsiveness condition, fear of being single was a marginally significant predictor of romantic interest, $\beta=.21, p=.06$, such that those with stronger fear of being single were more romantically interested in the low responsiveness target than those with weaker fear of being single. Furthermore, while those with weaker fear of being single were more romantically interested in the high responsiveness target than the low responsiveness target, $\beta=.29, p=.007$, those with stronger fear of being single showed no difference in preference between the high responsiveness and low responsiveness targets, $\beta=$ $.05, n s$.

Another significant interaction at Level 2 was found between fear of being single and attractiveness condition, $\beta=-.20, p=.02$ (see Figure 4). Simple effects tests revealed that within Figure 4. Romantic interest as a function of target attractiveness and fear of being single in Study 5

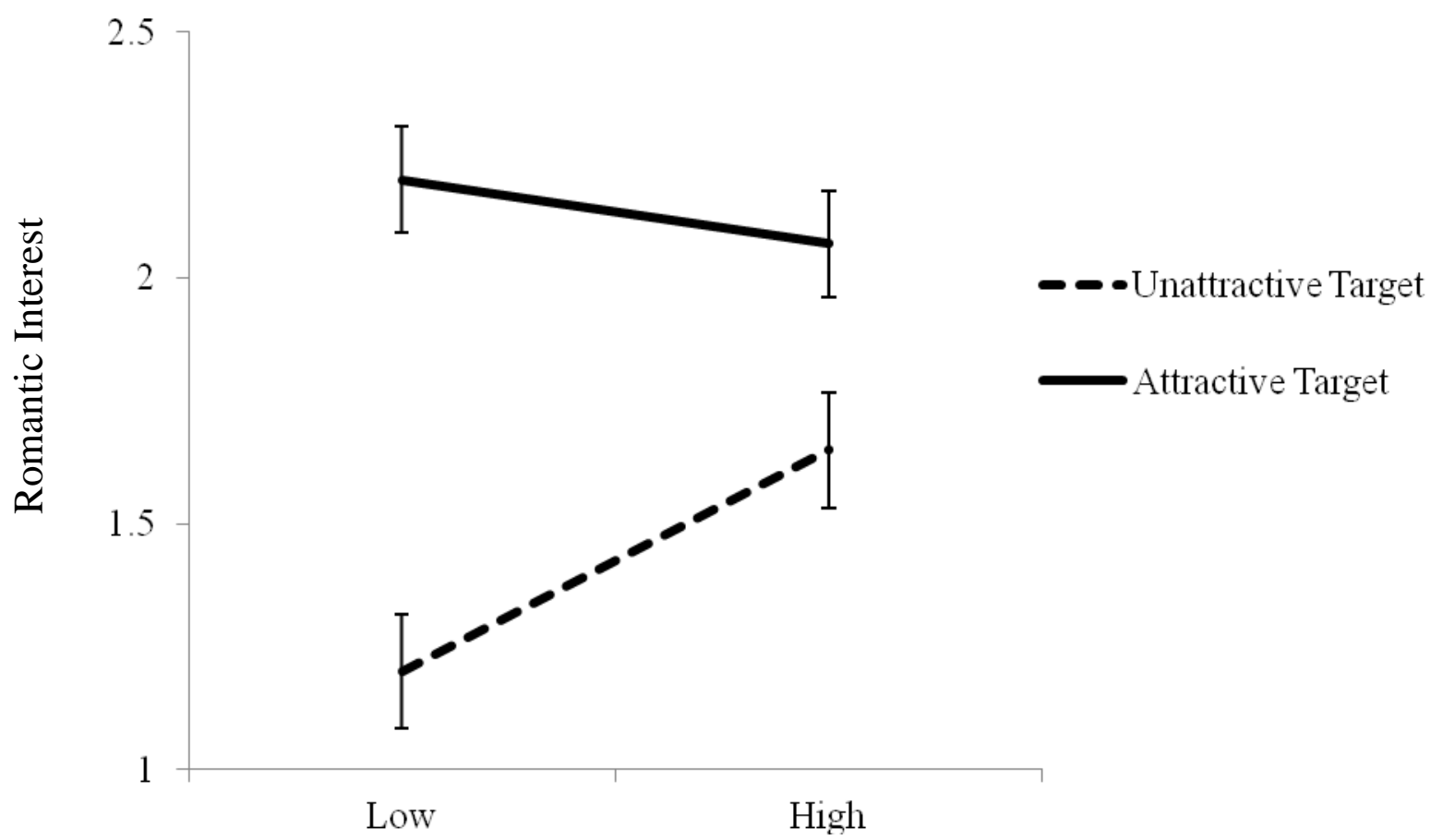

Fear of Being Single 
the attractive condition, fear of being single was not a significant predictor of romantic interest, $\beta$ $=-.07, n s$. However, within the unattractive condition, fear of being single was a marginally significant predictor of romantic interest, $\beta=.21, p=.06$, such that those with stronger fear of being single were more interested in the unattractive target than their more secure counterparts. Furthermore, those with weaker fear of being single expressed considerably greater interest in the attractive target compared to the unattractive target, $\beta=.48, p<.001$, whereas those with high fear of being single expressed only marginally greater interest in the attractive target, $\beta=$ $.20, p=.06$.

The two-way interaction between responsiveness condition and attractiveness condition was not significant, $\beta=.13, n s$, nor was the three-way interaction between all variables, $\beta=-.02$, $n s$. Inclusion of participant sex as a moderator in the model yielded a main effect of sex, $\beta=-.40$, $p<.001$, such that males expressed greater romantic interest than females. However, sex did not moderate the interaction between fear of being single and responsiveness condition, $\beta=.14, n s$, or the interaction between fear of being single and attractiveness condition, $\beta=.19, n s$. Inclusion of participant age as a moderator yielded a main effect of age, $\beta=-.13, p=.04$, such that older participants expressed less romantic interest in the targets. However, age also did not moderate the interaction between fear of being single and responsiveness condition, $\beta=.01, n s$, or the interaction between fear of being single and attractiveness condition, $\beta=.19, n s$.

The interaction between fear of being single and responsiveness condition was not significant when accounting for the main effect of anxious attachment and its interaction with responsiveness condition and attractiveness condition, $\beta=-.12$, ns. However, there was neither a significant main effect of anxious attachment, $\beta=.10, n s$, nor a significant interaction between anxious attachment and responsiveness condition, $\beta=-.08, n s$, nor a significant interaction between anxious attachment and attractiveness condition, $\beta=-.05$, $n s$. In other words, the fear of 
being single effects cannot be explained by anxious attachment.

\subsection{Anticipated Romantic Success}

Anticipated romantic success with the target was regressed onto online dating attitudes, fear of being single, responsiveness and attractiveness conditions, and all interactions, as above. There were main effects of responsiveness condition, $\beta=.40, p<.001$, as well as attractiveness condition, $\beta=.14, p=.02$, such that participants anticipated greater romantic success with the high responsiveness target than with the low responsiveness target, as well as with the attractive target compared to the unattractive target. As previously mentioned, online dating attitudes were a significant positive predictor of anticipated romantic success with the target, $\beta=.17, p=.007$. There was no main effect of fear of being single, $\beta=.06, n s$.

Replicating the results of Study 4, the interaction between fear of being single and responsiveness condition was not significant, $\beta=-.08, n s$, suggesting that those who fear being single do not necessarily express greater romantic interest in less responsive targets because they anticipate greater romantic success. However, there was a significant interaction between fear of being single and attractiveness condition, $\beta=-.17, p=.05$. When evaluating the attractive target, fear of being single did not predict anticipated romantic success, $\beta=-.008$, ns. However, when considering the unattractive target, fear of being single was a significant, positive predictor of anticipated romantic success, $\beta=.23, p=.04$. Examined differently, those with weaker fear of being single anticipated greater romantic success with the attractive target than the unattractive target, $\beta=.25, p=.03$, whereas those with stronger fear of being single anticipated equally high romantic success with both the attractive and unattractive targets, $\beta=.006, n s$. No other interactions were significant. Once again, these results hold when accounting for anxious and avoidant attachment. 
This pattern of findings suggests that anticipated romantic success may explain (i.e., mediate) why those high in fear of being single express greater romantic interest in the less attractive targets. In the analysis predicting romantic interest, including anticipated romantic success as a mediator (by including the main effect as well as the interaction with attractiveness condition to account for bias in the fear of being single by attractiveness condition interaction; Yzerbyt et al., 2004) reduced the fear of being single by attractiveness interaction to nonsignificance, $\beta=-.09, n s$, with anticipated romantic success a significant remaining predictor of romantic interest, $\beta=.67, p<.001$. A significant Sobel test confirmed full mediation, Sobel $=$ $1.92, p=.05$. There was, however, no evidence that romantic interest in less responsive dating targets is mediated by anticipated romantic success with those targets.

\section{Study 5 Discussion}

Those with stronger fear of being single appear to be willing to settle for less during mate selection. The results of Study 5 replicate those of Study 4, indicating that those with stronger fear of being single express relatively high romantic interest in less responsive dating partners. As in Study 4, participants generally recognized that the less responsive targets were in fact less responsive. However, despite this acknowledgment, those who feared being single expressed greater romantic interest in the unresponsive target than did their less fearful counterparts. Moreover, those who feared being single expressed relatively equal romantic interest in both the responsive and unresponsive targets. In other words, despite recognizing that some targets were less likely to be caring and supportive than others, those who feared being single did not seem to be taking this into account when making relationship decisions. Across both Studies 4 and 5, these results could not be accounted for by anxious attachment, suggesting that these effects cannot be attributed to insecurities more generally, but rather to insecurities about the prospect of 
being single specifically.

Anticipated romantic success did not serve to explain desires for less responsive dating targets. In other words, those who feared being single were not expressing romantic interest in less responsive people because they more easily imagined being able to form successful relationships with them. It is possible that selecting less responsive partners reflects a selfverification process for those who fear being single. To the extent that those who fear being single feel undeserving of a responsive partner (Swann, Wenzlaff, Krull, \& Pelham, 1992; Wood, Heimpel, Manwell, \& Whittington, 2009), selecting less responsive partners may serve to validate their feelings that they are undeserving of a fulfilling relationship and destined to be alone.

The results of Study 5 revealed that those who fear being single may be willing to settle for lower quality partners on multiple dimensions, not exclusively partners low in responsiveness. Specifically, those who feared being single also expressed greater romantic interest in unattractive dating targets compared to their less fearful counterparts, and reported a smaller difference in interest between the attractive and unattractive targets compared to those who did not fear being single. Unlike the responsiveness findings, the greater interest in low attractiveness was explained by anticipation of greater romantic success. In fact, those who feared being single may have been attuned to the benefits of settling for a less physically attractive partner. A partner's lack of physical attractiveness may limit their romantic alternatives (e.g., Buss \& Shackelford, 2008; Feingold, 1990), reducing one's mate competition and promoting the partner's romantic investment in the relationship (Rusbult et al., 1998). In this way, those who fear being single may be capable of securing their future relationship status if they are willing to settle for less attractive mates.

Study 5 further extended the results of Study 4 in several ways. Most importantly, Study 
5 included both male and female participants. As I have noted a lack of sex effects in the earlier studies, participant sex did not seem to play a role in the extent to which those who feared being single were willing to settle for less. This was true regardless of whether participants were considering attractiveness or responsiveness. Furthermore, the dating targets in Study 5 also varied not only in responsiveness but also in physical attractiveness, demonstrating multiple domains in which those who fear being single may be willing to settle for less. Finally, the measure of romantic interest in Study 5 reflected more explicit romantic desire for the targets than did that of Study 4. When aggregated to form an overall measure of romantic interest reflecting desires to approach the target, the replication of results from Study 4 provides a strong demonstration of the extent to which those who fear being single may be willing to settle for less. While participants in Study 4 evaluated romantic interest largely in terms of the target's general desirability and romantic appeal, participants in Study 5 evaluated romantic interest in terms of specific desires for sex and a relationship. The fact that participants were willing to acknowledge desires for sex and formation of exclusive relationships with unresponsive and unattractive targets highlights the powerful effects of fear of being single. 


\section{Chapter 7 \\ General Discussion}

The present research suggests that those who fear being single may lower their relationship standards without realizing it. Studies 1, 2A and 2B explored the content of people's fears about being single. From this, a valid and reliable Fear of Being Single Scale was created. Study 2C examined individuals in relationships and found that higher scores on the Fear of Being Single scale predicted greater dependence on less satisfying relationships. As such, Study 2C provided preliminary evidence that those who fear being single may be willing to settle for less when maintaining their relationships. Studies 3A and 3B showed that fear of being single was unrelated to ideal standards (i.e., the image of one's dream mate) and the bare minimum standards for which one would be willing to settle. This was the case for standards regarding appearance, resources, and being a good partner. Indeed, the only reliable effect in these studies was that those who fear being single expressed higher standards for finding a partner with good parenting skills. These studies suggest that those who fear being single do not consciously acknowledge a willingness to settle for less in relationships. However, Studies 4 and 5 showed that those who fear being single were romantically interested in less responsive and less physically attractive targets. Furthermore, those who feared being single were equally romantically interested in both desirable and undesirable targets even when they doubted their ability to have successful relationships with these individuals.

Importantly, these effects held accounting for age and sex, and were found above and beyond more general insecurities typically discussed in relationship literature, such as neuroticism and anxious attachment. I found time and again that anxiously attached individuals experienced a higher degree of fear of being single. However, fear of being single and anxious 
attachment are not synonymous with one another, but are rather theoretically and statistically distinct constructs assessing unique aspects of relational insecurity. The present research documented vulnerability to compromising one's standards for a relationship related to fear of being single that were not related to anxious attachment. Taken together, the present research highlights the individual differences in fear of being single, and demonstrates important consequences for relationship decisions.

One key variable on which those high in fear of being single were willing to compromise was partner responsiveness. Partner responsiveness is arguably one of the most fundamental components of satisfying, committed relationships (Maisel \& Gable, 2009; Reis et al., 2004). It is a pivotal marker of high quality, lasting relationships (Huston, Caughlin, Houts, Smith, \& George, 2001; Karney \& Bradbury, 1995). It is unfortunate, therefore, that those who fear being single may not be selecting partners on this trait. For one who fears being single, a responsive partner may provide the support and security needed to assuage concerns about abandonment, relationship dissolution, and future singlehood. As it stands, those who fear being single may be engaging in a self-fulfilling prophecy, such that they unselectively initiate relationships with less responsive partners, who subsequently treat them poorly or dissolve the relationship, further amplifying their concerns about being unable to maintain a relationship and risk being single in the long-term.

In addition to the risk of propagating the cycle of fear in relationships by developing patterns of relationships with less responsive others, being less discriminating during mate selection may have important, and ironic, implications for individuals' ability to initiate new relationships. In contexts such as speed-dating, prospective dating partners seem to be aware when others are being unselective, despite the fact that they do not ever see the others' written responses regarding dating interest (Eastwick, Finkel, Mochon, \& Ariely, 2007; McClure et al., 
2010). Furthermore, such nonselective pursuit of relationships is perceived unfavorably by prospective dating partners. People tend not to want someone who seems to be chasing after every available dating prospect. As such, those who fear being single may be engaging in behavior that ultimately contributes to their likelihood of remaining single. By being less selective during mate selection, they may have more trouble attracting a partner, and thus end up staying single for longer.

It is interesting to note that those who feared being single were no more interested in the high responsiveness targets than their secure counterparts. It is not likely that the lack of association between fear of being single and romantic interest in highly responsive targets was due to a statistical ceiling effect in romantic interest for high responsiveness partners. In both Studies 4 and 5, scores of romantic interest in the high responsiveness target represented the entire range of the scale and were not skewed (skewness statistics were - .21 and .68 for Studies 4 and 5, respectively). Therefore, although there was sufficient statistical range for a positive relation between fear of being single and romantic interest in highly responsive targets, it did not emerge.

At first glance, one may consider that the present findings could be due to positive illusions regarding relationship partners. Perhaps those who fear being single are motivated to overlook faults in romantic partners or to pretend they are happy despite a poor relationship. However, many aspects of the present findings rule out the likelihood of positive illusions explaining my effects. It does not seem to be the case, for instance, that those who fear being single are willing to initiate and maintain relationships with lower quality partners because they optimistically perceived them as higher quality than they are. Rather, participants in Study 2C acknowledged that their current relationships were less satisfying. Similarly, participants in Studies 4 and 5 recognized that the less responsive targets were indeed less responsive and they 
recognized that a lasting romantic relationship would be less likely with less responsive targets. Despite these negative evaluations, however, those who feared being single were dependent on their less satisfying partners and romantically interested in less responsive targets compared to those who did not fear being single. Taken together, these findings suggest that positive illusions are not the central mechanism through which settling for less takes place for individuals who fear being single.

While starting a new relationship may ease the concerns of those who fear being single, selecting lower quality partners for a relationship may produce a fair degree of relational ambivalence. For instance, anxiously attached individuals experience strong ambivalence in their relationships (Locke, 2008; MacDonald, Locke, Spielmann, \& Joel, in press; Mikulincer, Shaver, Bar-On, \& Ein-Dor, 2010). As Joel and colleagues (2011) demonstrated, anxiously attached individuals tend to be ambivalent in their relational commitment due to conflicting pressures between being dissatisfied in their relationship while also being highly dependent. This finding parallels the results of Study $2 \mathrm{C}$ wherein participants with stronger fear of being single were more dependent on relatively dissatisfying relationships. A willingness to settle for lower quality partners may therefore produce a state of ambivalence for those who fear being single, such that they are dissatisfied but dependent. As a consequence, selecting lower quality partners at the relationship initiation stage (as in Studies 4 and 5) may ultimately lead to staying in a bad relationship over the long-term (as in Study 2C).

The present research highlights that fear of being single, although a unique construct, is reliably related to anxious attachment. Fear of being single and anxious attachment are theoretically similar in the extent to which individuals experience chronic neediness and insecurity. Both types of insecure individuals may be chronically concerned about attachment figure availability and excessively seek reassurance about an attachment figure's devotion (e.g., 
Mikulincer et al., 2000; Shaver, Schachner, \& Mikulincer, 2005). On the other hand, the key difference between fear of being single and anxious attachment may be the specificity of the attachment figure desired. Namely, those who fear being single may specifically require a romantic attachment figure to satisfy needs for security and responsiveness. In contrast, others may be able to find comfort with parents and close friends as attachment figures when they are single. For instance, in a study of middle-aged single adults, individuals reported relying heavily on best friends and siblings to meet their attachment needs (Schachner, Shaver, \& Gillath, 2008). The results of the present research suggest that those who fear being single settle for less in order to gain and maintain a romantic partner specifically as an attachment figure. Although anxiously attached individuals may also be prone to such compromising behaviors, the fear of being single construct may be more uniquely tapping into this motivation in predicting the willingness to settle for less in the romantic domain.

While the present research has several strengths, including diverse samples of students and community members, a bottom-up approach to scale development and validation that includes qualitative and quantitative approaches, and consistent replication of key findings, the primary limitation of the present research is the exclusive focus on avoidance-based motivations. This research focuses solely on perceptions of threat when it comes to being single, and does not address perceived rewards of being single that may motivate approach of singlehood, as well as perceived romantic reward that may motivate approach of a relationship (e.g., Spielmann, Macdonald, \& Tackett, 2012). While participants' open-ended responses in Study 1 provided some insight into the rewards of singlehood, such as independence and close connections with friends and family members, the wording of the question still prompted participants to focus on reasons for "not fearing being single" rather than explicitly wanting to be single. Future research would benefit from an exploration of the perceived rewards of being single and the relative 
influence of approach- and avoidance-based motivations when it comes to singlehood.

The present research also does not address the boundary conditions at which those who fear being single are not willing to settle for less. I find support for compromising standards across multiple domains, including partner responsiveness and attractiveness. However, in this research, the targets under consideration were far from the least attractive and least responsive targets possible. This was necessary because I wanted the online dating profiles to seem realistic. Given that people have a tendency to put their best face forward to get a date (Gibbs, Ellison, \& Heino, 2006; Rowatt, Cunningham, \& Druen, 1998), it would have been out of the ordinary to have someone depict themselves in an extremely unfavorable light. Despite this limitation, however, the fact that I did not find an interaction between target responsiveness, target attractiveness, and fear of being single suggests that even targets with the unique combination of lower responsiveness and lower attractiveness were more desired by individuals who feared being single. Therefore, although targets were not at the extreme low ends of responsiveness and attractiveness, fear of being single predicted settling for less even in the least desirable circumstances in the present study. I cannot speculate on how undesirable a target would need to be before someone who fears being single would not be willing to be with them. Future research should explore how "low" those who fear being single will truly go.

The circumstances under which those who fear being single are willing to settle for less should also be examined. The present research found that fear of being single did not predict settling for less when considering hypothetical partners (Studies 3A and 3B), yet it did predict settling for less when considering actual targets (Studies 4 and 5). It is possible, therefore, that face-to-face interactions with prospective dating targets may predict even greater willingness to settle for less. Recent research suggests that romantic interest in written profiles is guided more directly by ideal partner preferences than it is in live interactions (Eastwick, Finkel, \& Eagly, in 
press). Although I found that self-reported standards were not generally predictive of settling for less when considering profiles of prospective targets, it is likely that a live interaction with someone directly expressing romantic interest would leave those who fear being single with less ability to decline their advances, regardless of the degree to which targets match their ideal standards.

The present research focuses only on a cross-section of people's experience with fear of being single. It does not shed light on the antecedents or long-term consequences of such fears. While some of the open-ended responses in Study 1 indicated that past experiences of heartbreak or loneliness affected their feelings about being single (either for better or worse), the present research does not clearly examine the root of fears about being single. It is unclear whether these fears are prompted primarily by experiences of romantic rejection, prolonged singlehood, or other factors. Future research should further explore the antecedents of fears about being single to inform methods for preventing or resolving such insecurities in their early stages. Similarly, future research should explore the long-term effects of fear of being single. Does selecting a relationship partner lower in responsiveness exacerbate fears of being single over time? Does a stable, fulfilling relationship alleviate fears over time? Research on insecure attachment styles suggests that repeated experiences with validating, responsive partners can slowly increase security over time (e.g., Fuller \& Fincham, 1995; Mikulincer \& Shaver, 2007; Ruvolo, Fabin, \& Ruvolo, 2001). While this may be the case with fear of being single as well, it is also possible that such relationship experience heightens one's fears of losing the current partner in particular. Future research could examine whether length of the relationship produces different factor loadings for concerns about one's specific relationship vs. being single more generally.

In conclusion, the extent to which one fears being single appears to have important consequences for relationship decisions. In contexts of relationship initiation and maintenance, 
those who fear being single may prioritize relationship status over and above relationship quality, settling for less responsive and less attractive partners and remaining in relationships that are less satisfying. This is the first research to empirically explore chronic concerns about singlehood, and it suggests that fear of being single may be an important construct to consider in relationship research. 


\section{References}

Ainsworth, M. D. S., \& Bell, S. M. (1970). Attachment, exploration, and separation: Illustrated by the behavior of one-year-olds in a strange situation. Child Development, 41, 49-67. doi: $10.2307 / 1127388$

Anderson, C., \& Stewart, S. (1994). Flying solo: Single women in midlife. New York: W. W. Norton.

Attridge, M., Berscheid, E., \& Sprecher, S. (1998). Dependency and insecurity in romantic relationships: Development and validation of two companion scales. Personal Relationships, 5, 31-58. doi: 10.1111/j.1475-6811.1998.tb00158.x

Baumeister, R. F., DeWall, C. N., Ciarocco, N. J., \& Twenge, J. M. (2005). Social exclusion impairs self-regulation. Journal of Personality and Social Psychology, 88, 589-604. doi: 10.1037/0022-3514.88.4.589

Baumeister, R. F., \& Leary, M. R. (1995). The need to belong: Desire for interpersonal attachments as a fundamental human motivation. Psychological Bulletin, 117, 497-529. doi: 10.1037/0033-2909.117.3.497

Bentler, P. M., \& Bonett, D. G. (1980). Significance tests and goodness of fit in the analysis of covariance structures. Psychological Bulletin, 88, 588-606. doi: 10.1037/00332909.88.3.588

Blackhart, G. C., Nelson, B. C., Knowles, M. L., \& Baumeister, R. F. (2009). Rejection elicits emotional reactions but neither causes immediate distress nor lowers self-esteem: A meta-analytic review of 192 studies on social exclusion. Personality and Social Psychology Review, 13, 269-309. doi: 10.1177/1088868309346065

Bowlby, J. (1969). Attachment and Loss, Vol. 1: Attachment. New York: Basic Books. 
Browne, M. W., \& Cudeck, R. (1993). Alternative ways of assessing model fit. In K. A. Bollen \& J. S. Long (Eds.), Testing structural equation models (pp. 132-162). Beverley Hills, CA: Sage.

Buss, D. M., \& Shackelford, T. K. (2008). Attractive women want it all: Good genes, economic investment, parenting proclivities, and emotional commitment. Evolutionary Psychology, 6, 134-146.

Campbell, L., Simpson, J. A., Kashy, D. A., \& Fletcher, G. J. O. (2001). Ideal standards, the self, and flexibility of ideals in close relationships. Personality and Social Psychology Bulletin, 27, 447-462. doi: 10.1177/0146167201274006

Caporeal, L. R. (2001). Evolutionary psychology: Towards a unifying theory and a hybrid science. Annual Review of Psychology, 52, 607-628. doi: 10.1146/annurev.psych.52.1.607

Chow, R. M., Tiedens, L. Z., \& Govan, C. L. (2008). Excluded emotions: The role of anger in antisocial responses to ostracism. Journal of Experimental Social Psychology, 44, 896903. doi: 10.1016/j.jesp.2007.09.004

Cohen, S., Doyle, W. J., Skoner, D. P., Rabin, B. S., \& Gwaltney, J. M. Jr. (1997). Social ties and susceptibility to the common cold. The Journal of the American Medical Association, 277, 1940-1944. doi: 10.1001/jama.1997.03540480040036

Cole, M. L. (1999). The experience of never-married women in their thirties who desire marriage and children. Doctoral dissertation, Institute for Clinical Social Work.

Cox, C. R., \& Arndt, J. (2012). How sweet it is to be loved by you: The role of perceived regard in the terror management of close relationships. Journal of Personality and Social Psychology, 102, 616-632. doi: 10.1037/a0025947

Cox, C. R., Arndt, J., Pyszczynski, T., Greenberg, J., Abdollahi, A., \& Solomon, S. (2008). Terror management and adults' attachment to their parents: The safe haven remains. 
Journal of Personality and Social Psychology, 94, 696-717. doi: 10.1037/00223514.94.4.696

Davila, J., \& Bradbury, T. N. (2001). Attachment insecurity and the distinction between unhappy spouses who do and do not divorce. Journal of Family Psychology, 15, 371-393. doi: $10.1037 / 0893-3200.15 \cdot 3.371$

Day, M. V., Kay, A. C., Holmes, J. G., \& Napier, J. L. (2011). System justification and the defense of committed relationship ideology. Journal of Personality and Social Psychology, 101, 291-306. doi: 10.1037/a0023197

DePaulo, B. M., \& Morris, W. L. (2005). Singles in society and in science. Psychological Inquiry, 16, 57-83. doi: 10.1207/s15327965pli162\&3_01

Downey, G., \& Feldman, S. I. (1996). Implications of rejection sensitivity for intimate relationships. Journal of Personality and Social Psychology, 70, 1327-1343. doi: $10.1037 / 0022-3514.70 .6 .1327$

Eastwick, P. W., \& Finkel, E. J. (2008). Sex differences in mate preferences revisited: Do people know what they initially desire in a romantic partner? Journal of Personality and Social Psychology, 94, 245-264. doi: 10.1037/0022-3514.94.2.245

Eastwick, P. W., Finkel, E. J., \& Eagly, A. H. (in press). When and why do ideal partner preferences affect the process of initiating and maintaining romantic relationships? Journal of Personality and Social Psychology. doi: 10.1037/a0024062

Eastwick, P. W., Finkel, E. J., Mochon, D., \& Ariely, D. (2007). Selective versus unselective romantic desire: Not all reciprocity is created equal. Psychological Science, 18, 317-319. doi: $10.1111 /$ j.1467-9280.2007.01897.x

Elliot, A. J., Gable, S. L., \& Mapes, R. R. (2006). Approach and avoidance motivation in the social domain. Personality and Social Psychology Bulletin, 32, 378-391. doi: 
$10.1177 / 0146167205282153$

Feeney, J. A., \& Noller, P. (1990). Attachment style as a predictor of adult romantic relationships. Journal of Personality and Social Psychology, 58, 281-291. doi: $10.1037 / 0022-3514.58 .2 .281$

Feeney, J. A., Noller, P., \& Hanrahan, M. (1994). Assessing adult attachment. In M. B. Sperling \& W. H. Berman (Eds.), Attachment in adults: Clinical and developmental perspectives (pp. 128-152). New York: Guilford Press.

Feingold, A. (1990). Gender differences in effects of physical attractiveness on romantic attraction: A comparison across five research paradigms. Journal of Personality and Social Psychology, 59, 981-993. doi: 10.1037/0022-3514.59.5.981

Feldman, S., \& Downey, G. (1994). Rejection sensitivity as a mediator of the impact of childhood exposure to family violence on adult attachment behavior. Development and Psychopathology, 6, 231-247. doi: 10.1017/S0954579400005976

Fleiss, J. L. (1981). Statistical methods for rates and proportions (2nd ed.). New York: John Wiley.

Fletcher, G. J. O., \& Simpson, J. A. (2000). Ideal standards in close relationships: Their structure and functions. Current Directions in Psychological Science, 9, 102-105. doi: $10.1111 / 1467-8721.00070$

Fletcher, G. J. O., Simpson, J. A., \& Thomas, G. (2000). Ideals, perceptions, and evaluations in early relationship development. Journal of Personality and Social Psychology, 79, 933940. doi: $10.1037 / 0022-3514.79 .6 .933$

Fletcher, G. J. O., Simpson, J. A., Thomas, G., \& Giles, L. (1999). Ideals in intimate relationships. Journal of Personality and Social Psychology, 76, 72-89. doi: 10.1037/0022-3514.76.1.72 
Foley, R. (1995). The adaptive legacy of human evolution: A search for the environment of evolutionary adaptedness. Evolutionary Anthropology: Issues, News, and Reviews, 4, 194-203. doi: 10.1002/evan.1360040603

Fraley, R. C., Brumbaugh, C. C., \& Marks, M. J. (2005). The evolution and function of adult attachment: A comparative and phylogenetic analysis. Journal of Personality and Social Psychology, 89, 731-746. doi: 10.1037/0022-3514.89.5.751

Fraley, R. C., \& Davis, K. E. (1997). Attachment formation and transfer in young adults' close friendships and romantic relationships. Personal Relationships, 4, 131-144. doi: 10.1111/j.1475-6811.1997.tb00135.x

Frazier, P., Arikian, N., Benson, S., Losoff, A., \& Maurer, S. (1996). Desire for marriage and life satisfaction among unmarried heterosexual adults. Journal of Social and Personal Relationships, 13, 225-239. doi: 10.1177/0265407596132004

Fuller, T. L., \& Fincham, F. D. (1995). Attachment style in married couples: Relation to current marital functioning, stability over time, and method of assessment. Personal Relationships, 2, 17-34. doi: 10.1111/j.1475-6811.1995.tb00075.x

Gangestad, S. W., \& Simpson, J. A. (2000). The evolution of human mating: Trade-offs and strategic pluralism. Behavioral and Brain Sciences, 23, 573-644. doi: 10.1017/S0140525X0000337X

Geary, D. C. (2000). Evolution and proximate expression of human paternal investment. Psychological Bulletin, 126, 55-77. doi: 10.1037//0033-2909.126.1.55

Gibbs, J. L., Ellison, N. B., \& Heino, R. D. (2006). Self-presentation in online personals: The role of anticipated future interaction, self-disclosure, and perceived success in Internet dating. Communication Research, 33, 1-26. doi: 10.1177/0093650205285368

Gillath, O., Hart, J., Noftle, E. E., \& Stockdale, G. D. (2009). Development and validation of a 
state adult attachment measure (SAAM). Journal of Research in Personality, 43, 362373. doi: 10.1016/j.jrp.2008.12.009

Hazan, C., \& Shaver, P. (1987). Romantic love conceptualized as an attachment process. Journal of Personality and Social Psychology, 52, 511-524. doi: 10.1037/0022-3514.52.3.511

Hertel, J., Schütz, A., DePaulo, B. M., Morris, W. L., \& Stucke, T. S. (2007). She’s single, so what? How are singles perceived compared with people who are married? Zeitschrift für Familienforschung (Journal of Family Research), 19, 139-158.

Hirschberger, G., Florian, V., \& Mikulincer, M. (2002). The anxiety buffering function of close relationships: Mortality salience effects on the readiness to compromise mate selection standards. European Journal of Social Psychology, 32, 609-625. doi: 10.1002/ejsp.110

House, J. S., Landis, K. R., \& Umberson, D. (1988). Social relationships and health. Science, 241, 540-545. doi: 10.1126/science.3399889

Huston, T. L., Caughlin, J. P., Houts, R. M., Smith, S. E., \& George, L. J. (2001). The connubial crucible: Newlywed years as predictors of marital delight, distress, and divorce. Journal of Personality and Social Psychology, 80, 237-252. doi: 10.1037/0022-3514.80.2.237

Joel, S., MacDonald, G., \& Plaks, J. E. (2012). Decision making and romantic relationships: Integrating two research fields. Manuscript under review.

Joel, S., MacDonald, G., \& Shimotomai, A. (2011). Conflicting pressures on relationship commitment for anxiously attached individuals. Journal of Personality, 79, 51-71. doi: 10.1111/j.1467-6494.2010.00680.x

John, O. P., \& Srivastava, S. (1999). The Big Five Trait Taxonomy: History, measurement, and theoretical perspectives. In L. A. Pervin \& O. P. John (Eds.), Handbook of Personality: Theory and Research (2 $2^{\text {nd }}$ ed., pp. 102-138), New York: Guilford Press.

Karney, B. R., \& Bradbury, T. N. (1995). The longitudinal course of marital quality and stability: 
A review of theory, methods, and research. Psychological Bulletin, 118, 3-34. doi: 10.1037/0033-2909.118.1.3

Kavanagh, P. S., Robins, S. C., \& Ellis, B. J. (2010). The mating sociometer: A regulatory mechanism for mating aspirations. Journal of Personality and Social Psychology, 99, 120-132.

Knee, C. R., Canevello, A., Bush, A. L., \& Cook, A. (2008). Relationship-contingent self-esteem and the ups and downs of romantic relationships. Journal of Personality and Social Psychology, 95, 608-627. doi: 10.1037/0022-3514.95.3.608

Krueger, J., Heckhausen, J., \& Hundertmark, J. (1995). Perceiving middle-aged adults: Effects of stereotype-congruent and incongruent information. The Journals of Gerontology: Series B: Psychological Sciences and Social Sciences, 50, 82-93. doi: 10.1093/geronb/50B.2.P82

Landis, J. R., \& Koch, G. G. (1977). The measurement of observer agreement for categorical data. Biometrics, 33, 159-174. doi: 10.2307/2529310

Laurenceau, J-P., Feldman Barrett, L., \& Pietromonaco, P. R. (1998). Intimacy as an interpersonal process: The importance of self-disclosure, partner disclosure, and perceived partner responsiveness in interpersonal exchanges. Journal of Personality and Social Psychology, 74, 1238-1251. doi: 10.1037/0022-3514.74.5.1238

Laurenceau, J-P., \& Kleinman, B. M. (2006). Intimacy in personal relationships. In A. L. Vangelisti \& D. Perlman (Eds.), Cambridge handbook of personal relationships (pp. 637-653). New York: Cambridge University Press.

Le, B., Dove, N. L., Agnew, C. R., Korn, M. S., \& Mutso, A. A. (2010). Predicting nonmarital romantic relationship dissolution: A meta-analytic synthesis. Personal Relationships, 17, 377-390. doi: 10.1111/j.1475-6811.2010.01285.x 
Leary, M. R., Kelly, K. M., Cottrell, C. A., \& Schreindorfer, L. S. (2007). Individual differences in the need to belong: Mapping the nomological network. Unpublished manuscript.

Leary M. R., \& Springer, C. A. (2001). Hurt feelings: The neglected emotion. In R. M. Kowalski (Ed.), Behaving badly: Aversive behaviors in interpersonal relationships (pp. 151-175). Washington, DC: American Psychological Association.

Leary, M. R., Twenge, J. M., \& Quinlivan, E. (2006). Interpersonal rejection as a determinant of anger and aggression. Personality and Social Psychology Review, 10, 111-132. doi: $10.1207 / \mathrm{s} 15327957 \mathrm{pspr} 1002 \_2$

Locke, K. D. (2008). Attachment styles and interpersonal approach and avoidance goals in everyday couple interactions. Personal Relationships, 15, 359-374. doi: 10.1111/j.14756811.2008.00203.x

Loewenstein, G. (1996). Out of control: Visceral influences on behavior. Organizational Behavior and Human Decision Processes, 65, 272-292. doi:10.1006/obhd.1996.0028

Maisel, N. C., \& Gable, S. L. (2009). The paradox of received social support: The importance of responsiveness. Psychological Science, 20, 928-932. doi: 10.1111/j.14679280.2009.02388.x

MacDonald, G., Locke, K. D., Spielmann, S. S., \& Joel, S. (in press). Insecure attachment predicts ambivalent social threat and reward perceptions in romantic relationships. Journal of Social and Personal Relationships.

MacDonald, G., Tackett, J. L., \& Bakker, N. (2012). Curb your enthusiasm: Attachment avoidance predicts low expectations of social reward. Manuscript under review. Markiewicz, D., Lawford, H., Doyle, A. B., \& Haggart, N. (2006). Developmental differences in adolescents' and young adults' use of mothers, fathers, best friends, and romantic 
partners to fulfill attachment needs. Journal of Youth and Adolescence, 35, 121-134. doi: 10.1007/s10964-005-9014-5

McClure, M. J., Lydon, J. E., Baccus, J. R., \& Baldwin, M. W. (2010). A signal detection analysis of chronic attachment anxiety at speed dating: Being unpopular is only the first part of the problem. Personality and Social Psychology Bulletin, 36, 1024-1036. doi: $10.1177 / 0146167210374238$

Mikulincer, M., Birnbaum, G., Woddis, D., \& Nachmias, O. (2000). Stress and accessibility of proximity-related thoughts: Exploring the normative and intraindividual components of attachment theory. Journal of Personality and Social Psychology, 78, 509-523. doi: 10.1037/0022-3514.78.3.509

Mikulincer, M., Gillath, O., \& Shaver, P. R. (2002). Activation of the attachment system in adulthood: Threat-related primes increase the accessibility of mental representations of attachment figures. Journal of Personality and Social Psychology, 83, 881-895. doi: $10.1037 / 0022-3514.83 .4 .881$

Mikulincer, M., \& Shaver, P. R. (2007). Attachment in adulthood: Structure, Dynamics, and Change. New York: Guilford Press.

Mikulincer, M., Shaver, P. R., Bar-On, N., \& Ein-Dor, T. (2010). The pushes and pulls of close relationships: Attachment insecurities and relational ambivalence. Journal of Personality and Social Psychology, 98, 450-468. doi: 10.1037/a0017366

Morris, W. L., Sinclair, S., \& DePaulo, B. M. (2007). No shelter for singles: The perceived legitimacy of marital status discrimination. Group Processes \& Intergroup Relations, 10, 457-470. doi: 10.1177/1368430207081535

Murray, S. L., Derrick, J. L., Leder, S., \& Holmes, J. G. (2008). Balancing connectedness and self-protection goals in close relationships: A levels-of-processing perspective on risk 
regulation. Journal of Personality and Social Psychology, 94, 429-459. doi:

10.1037/0022-3514.94.3.429

Murray, S. L., \& Holmes, J. G. (1993). Seeing virtues in faults: Negativity and the transformation of interpersonal narratives in close relationships. Journal of Personality and Social Psychology, 65, 707-722. doi: 10.1037/0022-3514.65.4.707

Murray, S. L., Holmes, J. G., \& Griffin, D. W. (2000). Self-esteem and the quest for felt security: How perceived regard regulates attachment processes. Journal of Personality and Social Psychology, 78, 478-498. doi: 10.1037//0022-3514.78.3.478

Murray, S. L., Holmes, J. G., MacDonald, G., \& Ellsworth, P. C. (1998). Through the looking glass darkly? When self-doubts turn into relationship insecurities. Journal of Personality and Social Psychology, 75, 1459-1480. doi: 10.1037/0022-3514.75.6.1459

Noftle, E. E., \& Gillath, O. (2009). Applying lesions from the person-situation debate to attachment theory and research. Journal of Research in Personality, 43, 260-261. doi: 10.1016/j.jrp.2008.12.024

Radloff, L. S. (1977). The CES-D scale: A self-report depression scale for research in the general population. Applied Psychological Measurement, 1, 385-401. doi: $10.1177 / 014662167700100306$

Regan, P. C. (1998). What if you can't get what you want? Willingness to compromise ideal mate selection standards as a function of sex, mate value, and relationship context. Personality and Social Psychology Bulletin, 24, 1294-1303. doi: $10.1177 / 01461672982412004$

Reis, H. T., Clark, M. S., \& Holmes, J. G. (2004). Perceived partner responsiveness as an organizing construct in the study of intimacy and closeness. In D. J. Mashek \& A. P. Aron (Eds.), Handbook of closeness and intimacy (pp. 201-225). Mahwah, NJ: Erlbaum. 
Reynolds, J., \& Taylor, S. (2005). Narrating singleness: Life stories and deficit identities. Narrative Inquiry, 15, 197-215. doi: 10.1075/ni.15.2.02rey

Reynolds, J., \& Wetherell, M. (2003). The discursive climate of singleness: The consequences for women's negotiation of a single identity. Feminism and Psychology, 13, 489-510. doi: $10.1177 / 09593535030134014$

Rowatt, W. C., Cunningham, M. R., \& Druen, P. B. (1998). Deception to get a date. Personality and Social Psychology Bulletin, 24, 1228-1242. doi: 10.1177/01461672982411009

Rusbult, C. E., \& Martz, J. M. (1995). Remaining in an abusive relationship: An investment model analysis of nonvoluntary dependence. Personality and Social Psychology Bulletin, 21, 558-571. doi: 10.1177/0146167295216002

Rusbult, C. E., Martz, J. M., \& Agnew, C. R. (1998). The Investment Model Scale: Measuring commitment level, satisfaction level, quality of alternatives, and investment size. Personal Relationships, 5, 357-391. doi: 10.1111/j.1475-6811.1998.tb00177.x

Russell, D., Peplau, L. A., \& Cutrona, C. E. (1980). The revised UCLA loneliness scale: Concurrent and discriminant validity evidence. Journal of Personality and Social Psychology, 39, 472-480. doi: 10.1037/0022-3514.39.3.472

Ruvolo, A. P., Fabin, L. A., \& Ruvolo, C. M. (2001). Relationship experiences and change in attachment characteristics of young adults: The role of relationship breakups and conflict avoidance. Personal Relationships, 8, 265-281. doi: 10.1111/j.1475-6811.2001.tb00040.x

Schachner, D. A., Shaver, P. R., \& Gillath, O. (2008). Attachment style and long-term singlehood. Personal Relationships, 15, 479-491. doi: 10.1111/j.1475-6811.2008.00211.x

Schwartzberg, N., Berliner, K., \& Jacob, D. (1995). Single in a married world: A life cycle framework for working with the unmarried adult. New York: W. W. Norton.

Sharp, E. A., \& Ganong, L. (2007). Living in the gray: Women's experiences of missing the 
marital transition. Journal of Marriage and Family, 69, 831-844. doi: 10.1111/j.17413737.2007.00408.x

Sharp, E. A., \& Ganong, L. (2011). “I'm a loser, I'm not married, let's just all look at me”: Eversingle women's perceptions of their social environment. Journal of Family Issues, 32, 956-980. doi: 10.1177/0192513X10392537

Shaver, P. R., Schachner, D. A., \& Mikulincer, M. (2005). Attachment style, excessive reassurance seeking, relationship processes, and depression. Personality and Social Psychology Bulletin, 31, 343-359. doi: 10.1177/0146167204271709

Slotter, E. B., \& Finkel, E. J. (2009). The strange case of sustained dedication to an unfulfilling relationship: Predicting commitment and breakup from attachment anxiety and need fulfillment within relationships. Personality and Social Psychology Bulletin, 35, 85-100. doi: $10.1177 / 0146167208325244$

Spielmann, S. S., Maxwell, J. A., MacDonald, G., \& Baratta, P. L. (in press). Don’t get your hopes up: Avoidantly attached individuals perceive lower social reward when there is potential for intimacy. Personality and Social Psychology Bulletin.

Spielmann, S. S., MacDonald, G., \& Tackett, J. L. (2012). Social threat, social reward, and regulation of investment in romantic relationships. Personal Relationships, 19, 601-622. doi: 10.1111/j.1475-6811.2011.01377.x

Swann, W. B., Wenzlaff, R. M., Krull, D. S., \& Pelham, B. W. (1992). Allure of negative feedback: Self-verification strivings among depressed persons. Journal of Abnormal Psychology, 101, 293-306. doi: 10.1037/0021-843X.101.2.293

Thornton, A., \& Young-DeMarco, L. (2001). Four decades of trends in attitudes toward family issues in the United States: The 1960s through the 1990s. Journal of Marriage and Family, 63, 1009-1037. doi: 10.1111/j.1741-3737.2001.01009.x 
Tolmacz, R. (2004). Attachment style and willingness to compromise when choosing a mate. Journal of Social and Personal Relationships, 21, 267-272. doi: $10.1177 / 0265407504041387$

U.S. Census Bureau. (2010). Households and families: 2010. Retrieved May 30, 2012 from, http://www.census.gov/prod/cen2010/briefs/c2010br-14.pdf

Wieselquist, J., Rusbult, C. E., Foster, C. A., \& Agnew, C. R. (1999). Commitment, prorelationship behavior, and trust in close relationships. Journal of Personality and Social Psychology, 77, 942-966. doi: 10.1037/0022-3514.77.5.942

Wildermuth, S. M. (2004). The effects of stigmatizing discourse on the quality of on-line relationships. CyberPsychology and Behavior, 7, 73-84. doi:

$10.1089 / 109493104322820147$

Wood, D., \& Brumbaugh, C. C. (2009). Using revealed mate preferences to evaluate market force and differential preference explanations for mate selection. Journal of Personality and Social Psychology, 96, 1226-1244. doi: 10.1037/a0015300

Wood, J. V., Heimpel, S. A., Manwell, L. A., \& Whittington, E. J. (2009). This mood is familiar and I don't deserve to feel better anyway: Mechanisms underlying self-esteem differences in motivation to repair sad moods. Journal of Personality and Social Psychology, 96, 363-380. doi: 10.1037/a0012881

Yzerbyt, V. Y., Muller, D., \& Judd, C. M. (2004). Adjusting researchers' approach to adjustment: On the use of covariates when testing interactions. Journal of Experimental Social Psychology, 40, 424-431. doi: 10.1016/j.jesp.2003.10.001 


\section{Appendix A: Original items for Fear of Being Single scale}

Please respond to the following items using the scale provided.

123

Not at all true
4

5

Very true

1. I fear being alone when I am old.

2. I feel like I'm supposed to be in a serious romantic relationship by now.

3. I sometimes feel as though everyone is in a relationship except for me.

4. It scares me to think that there might not be anyone out there for me.

5. People who never date or marry are kind of sad.

6. I feel it is close to being too late for me to find the love of my life.

7. I feel anxious when I think about being single forever.

8. I need to find a partner before I'm too old to have and raise children.

9. If I end up alone in life, I will probably feel like there is something wrong with me.

10. I would rather be with someone whom I do not love than be alone.

11. It doesn't matter at all to me how old I might be when/if I find someone. (R)

12. I worry about how others will judge me if I am ever single for too long.

13. If I never marry, I'll have a lonely life.

14. As I get older, it will get harder and harder to find someone.

15. My friends and family are enough to keep me happy without a romantic partner. (R)

16. I am perfectly fine with the idea of never settling down with someone. (R)

17. Getting older will inevitably make me a less desirable romantic partner. 